\title{
Integrated Physiological, Transcriptomic, and Metabolomic Analyses Revealed Molecular Mechanism for Salt Resistance in Soybean Roots
}

\author{
Jie Jin ${ }^{1}$, Jianfeng Wang ${ }^{2,3}{ }^{\oplus}$, Keke Li ${ }^{1}$, Shengwang Wang ${ }^{1}$, Juan Qin ${ }^{1}$, Guohong Zhang ${ }^{4}$, Xiaofan Na ${ }^{1}$, \\ Xiaomin Wang ${ }^{1, *}$ and Yurong $B i^{1, *}$ (D)
}

1 Ministry of Education Key Laboratory of Cell Activities and Stress Adaptations, School of Life Sciences, Lanzhou University, Lanzhou 730000, China; jinj2015@lzu.edu.cn (J.J.); likk17@lzu.edu.cn (K.L.); wangshw16@lzu.edu.cn (S.W.); qinj18@lzu.edu.cn (J.Q.); naxf@lzu.edu.cn (X.N.)

2 State Key Laboratory of Plateau Ecology and Agriculture, Qinghai University, Xining 810016, China; wangjf12@lzu.edu.cn

3 Center for Grassland Microbiome, Collaborative Innovation Center for Western Ecological Safety, State Key Laboratory of Grassland Agro-Ecosystems, College of Pastoral Agriculture Science and Technology, Lanzhou University, Lanzhou 730000, China

4 Institute of Dryland Agriculture, Gansu Academy of Agricultural Sciences, Lanzhou 730070, China; zgh@gsagr.ac.cn

* Correspondence: wangxiaomin@lzu.edu.cn (X.W.); yrbi@lzu.edu.cn (Y.B.)

\section{check for} updates

Citation: Jin, J.; Wang, J.; Li, K.; Wang, S.; Qin, J.; Zhang, G.; Na, X.; Wang, X.; Bi, Y. Integrated Physiological, Transcriptomic, and Metabolomic Analyses Revealed Molecular Mechanism for Salt Resistance in Soybean Roots. Int. J. Mol. Sci. 2021, 22, 12848. https:// doi.org/10.3390/ijms222312848

Academic Editor: Juan Manuel Ruiz Lozano

Received: 5 November 2021

Accepted: 22 November 2021

Published: 27 November 2021

Publisher's Note: MDPI stays neutral with regard to jurisdictional claims in published maps and institutional affiliations.

Copyright: (c) 2021 by the authors. Licensee MDPI, Basel, Switzerland. This article is an open access article distributed under the terms and conditions of the Creative Commons Attribution (CC BY) license (https:/ / creativecommons.org/licenses/by/ $4.0 /)$

\begin{abstract}
Salinity stress is a threat to yield in many crops, including soybean (Glycine max L.). In this study, three soybean cultivars (JD19, LH3, and LD2) with different salt resistance were used to analyze salt tolerance mechanisms using physiology, transcriptomic, metabolomic, and bioinformatic methods. Physiological studies showed that salt-tolerant cultivars JD19 and LH3 had less root growth inhibition, higher antioxidant enzyme activities, lower ROS accumulation, and lower $\mathrm{Na}^{+}$ and $\mathrm{Cl}^{-}$contents than salt-susceptible cultivar LD2 under $100 \mathrm{mM} \mathrm{NaCl}$ treatment. Comparative transcriptome analysis showed that compared with LD2, salt stress increased the expression of antioxidant metabolism, stress response metabolism, glycine, serine and threonine metabolism, auxin response protein, transcription, and translation-related genes in JD19 and LH3. The comparison of metabolite profiles indicated that amino acid metabolism and the TCA cycle were important metabolic pathways of soybean in response to salt stress. In the further validation analysis of the above two pathways, it was found that compared with LD2, JD19, and LH3 had higher nitrogen absorption and assimilation rate, more amino acid accumulation, and faster TCA cycle activity under salt stress, which helped them better adapt to salt stress. Taken together, this study provides valuable information for better understanding the molecular mechanism underlying salt tolerance of soybean and also proposes new ideas and methods for cultivating stress-tolerant soybean.
\end{abstract}

Keywords: transcriptome; metabolome; amino acid; nitrogen metabolism; nitrogen use efficiency; TCA cycle; salt stress; soybean

\section{Introduction}

Salt stress is a major restricting factor in agricultural production [1,2]. The salinized soil currently accounts for $8 \%$ of the world's total land area, and it is expected that the area of irrigated agriculture and salt-affected farmland in semi-arid areas will double by 2050 [3]. In order to meet the fast-growing food demand for the global population, it is estimated that food production needs to increase by $70-110 \%$ to maintain current levels by 2050 [4]. Therefore, it is particularly crucial to enhance the salt tolerance of conventional crops without expanding agricultural land area [5].

Soybean (Glycine max L.), as one of the widely planted crops, accounts for about $56 \%$ of the total oilseed production in the world $[6,7]$. However, soybean is especially sensitive to 
salinity, and its yield is decreased by nearly $40 \%$ with the increased salt stress [8,9]. On the one hand, salinity stress can reduce the survival rate of rhizobia in the soil, thus inhibiting symbiotic nitrogen fixation and resulting in the reduction in soybean yield. On the other hand, the host plants are more salt-sensitive than rhizobia, which is a main limiting factor of yield under salt stress [10]. Therefore, improving the salt tolerance of soybean seedlings is vitally important to improve soybean production.

As the most soluble salt in soil, $\mathrm{NaCl}$ causes damages to plants in many diverse ways, including osmotic stress, ionic stress, oxidative stress, and nutritional disorders [11-13]. To cope with adverse high salinity environment, plants have to employ several adaptive strategies, for example, by inducing enzymatic scavengers, such as superoxide dismutase (SOD), peroxidase (POD), catalase (CAT), and ascorbate peroxidase (APX), to mitigate ROS stress and by decreasing $\mathrm{Na}^{+}$content and increasing $\mathrm{K}^{+}$content in the cytoplasm to keep the high $\mathrm{K}^{+} / \mathrm{Na}^{+}$level [14-18]. In addition, high salinity also alters many metabolic processes. The accumulation of proline, betaine, and sucrose is involved in the osmotic regulation of plants under salt stress [19]. Many organic acids, fatty acids, and phytohormones are changed to adapt to saline conditions [20]. It has been reported that the exogenous application of abscisic acid could ameliorate wheat growth under salinity stress [21]. Moreover, accumulation of free amino acids was observed in Arabidopsis exposed to salt stress [22]. Zhang et al. [23] demonstrated that seven amino acids were significantly enriched in tomatoes during the adaptation to salt stress.

Currently, the plant responses to salt stress have been widely studied at molecular and physiological levels. More and more molecular mechanisms have been revealed along with the progress of genomics, proteomics, and metabolomics. Huang et al. [24] used multi-omics analysis to reveal the mechanisms of salt resistance in sea barley. Xiong et al. [25] conducted transcriptomic analysis in alfalfa to clarify its salt adaptive strategies by up-regulating hormone signal transduction and the antioxidant gene expression. Zhang et al. [26] explored the different responses to salinity in sesame through metabonomic analysis and revealed that amino acid metabolism, sucrose, raffinose, and oligosaccharide metabolism were enhanced in salt-tolerant genotype. In this study, three soybean cultivars (JD19, LH3, and LD2) with different salt tolerance were used to investigate the mechanism and specific salt adaptive strategies. We integrated physiology, transcriptomic, and metabolomic analysis of JD19, LH3, and LD2 exposed to salinity stress to identify the key genes, metabolites, and metabolic pathways potentially contributing to salt tolerance and further verify the crucial metabolic pathways. The present study will provide valuable information for improving salt resistance in soybean and lay a foundation for crop improvement in the future.

\section{Results}

\subsection{Differences of Three Soybean Cultivars Response to Salt Stress}

It is well known that salt stress can change root architecture and biomass allocation [18]. As shown in Figure 1A, the root growth was different under salt stress among the three soybean cultivars. The primary root length in JD19 and LH3 was greater than that of LD2. A total of $100 \mathrm{mM} \mathrm{NaCl}$ treatment reduced the primary root length of JD19, LH3, and LD2 by approximately $19.8 \%, 20.7 \%$, and $36.8 \%$, respectively (Figure 1B). The numbers of lateral roots did not exhibit significant differences among LH3, LD2, and JD19 under the control condition. However, $100 \mathrm{mM} \mathrm{NaCl}$ treatment significantly decreased the lateral root numbers in all three cultivars, especially in LD2 (Figure 1C). Although the fresh weight and the dry weight in all cultivars were decreased under salt stress, JD19 and LH3 obviously lost less biomass than LD2 (Figure 1D,E). These results suggested that JD19 and LH3 were more tolerant to salinity than LD2. 

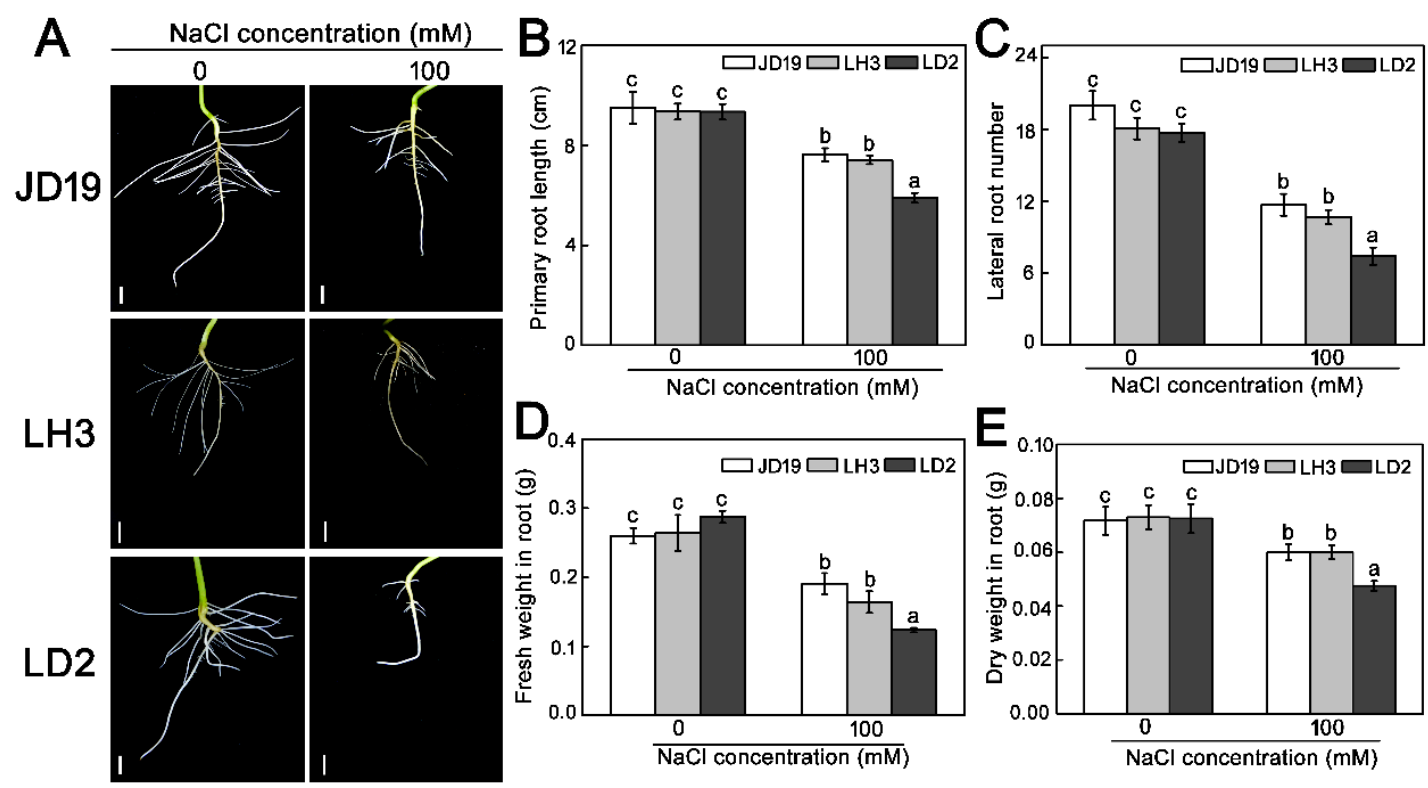

Figure 1. Root phenotype (A), primary root length (B), lateral root number (C), fresh weight (D), and dry weight (E) of three soybean cultivars under $100 \mathrm{mM} \mathrm{NaCl}$ treatment. Bar: $1 \mathrm{~cm}$. Data are means $\pm \mathrm{SE}(n=3)$. Different letters indicate significant difference at $p<0.05$.

To investigate whether ROS level is associated with different tolerance of three soybean genotypes, the $\mathrm{H}_{2} \mathrm{O}_{2}$, MDA contents, and antioxidant enzyme activities were analyzed. The activities of SOD, CAT, POD, and APX did not show significant differences among the three soybean cultivars without $\mathrm{NaCl}$ treatment. However, salt stress strongly increased the activities of the four antioxidant enzymes in roots, especially in JD19 and LH3 (Figure S1A-D). On the contrary, the contents of $\mathrm{H}_{2} \mathrm{O}_{2}$ and MDA were higher in LD2 than in JD19 and LH3 under salt stress (Figure S1E,F). Thus, high activities of antioxidant enzymes and low contents of $\mathrm{H}_{2} \mathrm{O}_{2}$ and MDA might be one of the reasons for salt tolerance in JD19 and LH3. Moreover, salt stress always leads to ion toxicity for plants. Figure 2 showed that ion contents did not show a significant difference among the three soybean cultivars without $\mathrm{NaCl}$ treatment. However, salt stress strongly stimulated $\mathrm{Na}^{+}$and $\mathrm{Cl}^{-}$ accumulation in three soybean roots and reduced the $\mathrm{K}^{+}$content (Figure 2 ). In comparison with JD19 and LH3, LD2 accumulated more $\mathrm{Na}^{+}, \mathrm{Cl}^{-}$and less $\mathrm{K}^{+}$contents in the root, which finally resulted in a higher level of $\mathrm{Na}^{+} / \mathrm{K}^{+}$ratio under salt stress. The $\mathrm{Na}^{+} / \mathrm{K}^{+}$ratio in JD19, LH3, and LD2 increased by 24.1\%, 24.5\%, and 32.9\%, respectively (Figure 2C).

\subsection{Transcriptional Characteristics of Three Soybean Cultivars Response to Salt Stress}

To gain further insight into the salt tolerance mechanism of soybean, root tissues of three soybean cultivars were collected with control and $100 \mathrm{mM} \mathrm{NaCl}$ treatment for transcription analysis. The mapping of clear reads to the soybean genome showed that $89.41 \%-93.76 \%$ of reads aligned to only one location in the reference genome (Table S1). A threshold of fold change $\geq 2$ and FDR $\leq 0.05$ was used to identify differentially expressed genes (DEGs). As shown in Figure 3A, a total of 1482 DEGs were identified in JD19, of which 837 genes were up-regulated, and 645 genes were down-regulated. A total of 1368 DEGs were identified in LH3, of which 739 genes were up-regulated, and 629 genes were down-regulated, and a total of 2116 DEGs were identified in LD2, of which 833 genes were up-regulated, and 1283 genes were down-regulated. Additionally, after $100 \mathrm{mM}$ $\mathrm{NaCl}$ treatment, 123 genes were induced, and 117 genes were repressed in all soybean genotypes (Figure 3B,C). A total of 183 up-regulated genes and 101 down-regulated genes were overlapped between the salt-tolerant genotypes JD19 and LH3 (Figure 3B,C). To test the RNA-seq data, we randomly selected five genes for qRT-PCR validation. The result 
of these genes by qRT-PCR was highly correlated with the RNA-seq data, which further proved the reliability of transcriptomic results (Table S2 and Figure S2).

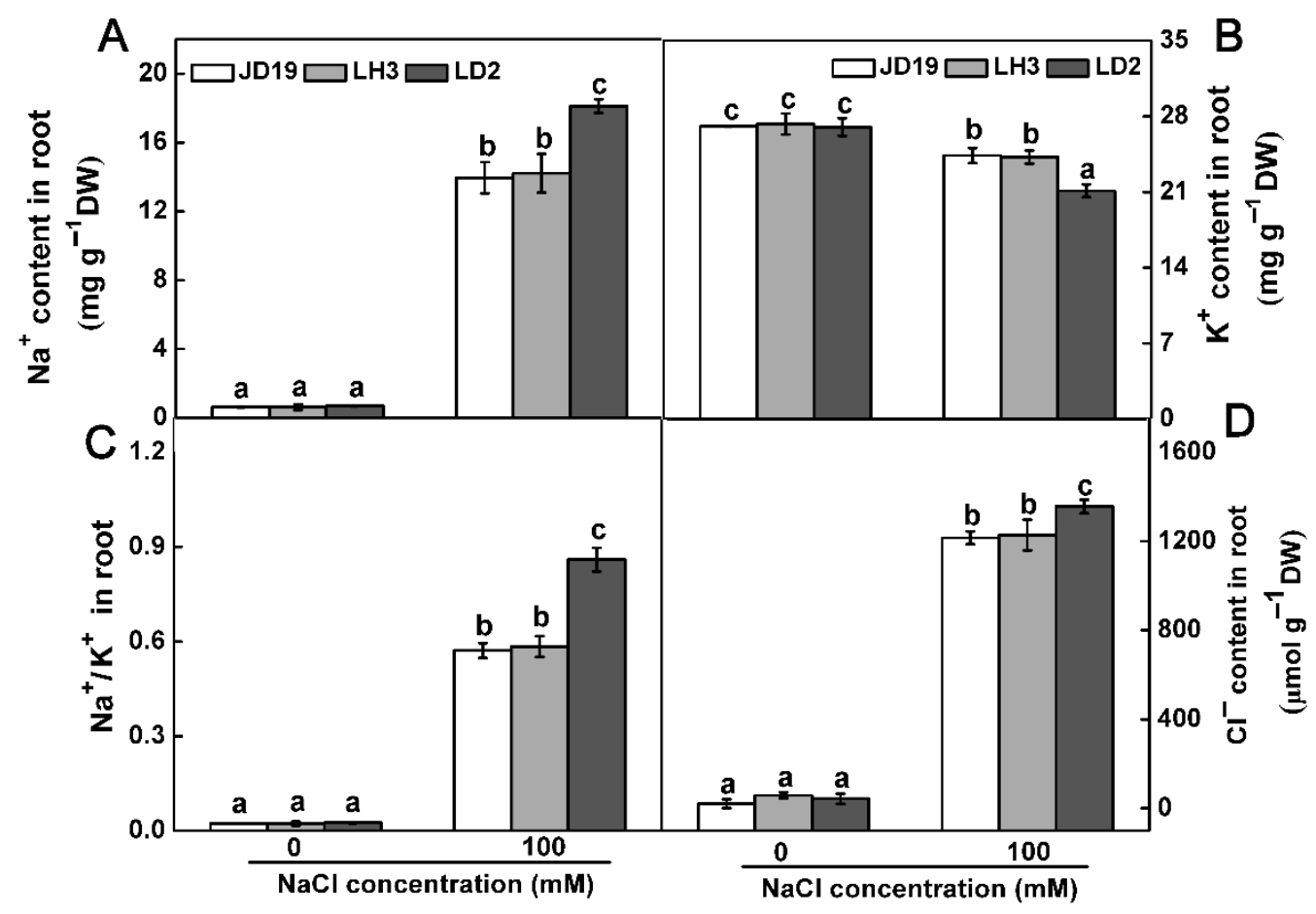

Figure 2. $\mathrm{Na}^{+}$content (A), $\mathrm{K}^{+}$content $(\mathbf{B}), \mathrm{Na}^{+}: \mathrm{K}^{+}$ratio (C), and $\mathrm{Cl}^{-}(\mathbf{D})$ content in roots of three soybean cultivars under $100 \mathrm{mM} \mathrm{NaCl}$ treatment. Data are the means $\pm \mathrm{SE}(n=3)$. Different letters indicate significant difference at $p<0.05$.

\subsection{Differentially Expressed Genes among JD19, LH3, and LD2}

Hierarchical clustering analysis showed that the commonly regulated genes exhibited differential expression among JD19, LH3, and LD2 in the saline condition (Figure S3A,B). GO and KEGG pathway enrichment analysis was used to explore the underlying function of key salt-responsive genes in soybean. The biological process of GO terms showed that the 123 up-regulated core genes in all cultivars were enriched in ammonium transmembrane transport, nitrogen utilization, sulfate assimilation, oxidation-reduction process, cellular redox homeostasis, response to oxidative stress, flavonoid biosynthesis, flavonoid metabolism, and small molecule metabolism. Biological processes of carbohydrate transmembrane transport, organic substance transport, transmembrane transport, adenine salvage, nitrogen compound transport, carbohydrate metabolic process, monovalent inorganic cation transport, citrate transport, anion transport, and regulation of transcription, DNA templated were enriched in 117 down-regulated core genes (Figure S3C,D). KEGG pathway enrichment analysis revealed that genes involved in protein processing in glyoxylate and dicarboxylate metabolism, zeatin biosynthesis, carbon metabolism were up-regulated by salt stress (Figure S3E). The together down-regulated DEGs in the three cultivars did not have the same significant enrichment of the KEGG pathway.

JD19 and LH3, as two salt-tolerant genotypes, jointly regulated some DEGs under salt stress, suggesting that these genes may function in salt tolerance of JD19 and LH3. GO term enrichment analysis revealed that the categories of glutathione metabolism process, response to stress, organic cation transport, transmembrane transport, and peptide metabolic process were enriched among genes that were up-regulated in JD19 and LH3 under salt stress (Figure 3D). Meanwhile, the categories of nodulation, regulation of RNA biosynthetic process, regulation of RNA metabolic process, glycerophospholipid metabolic process, purine-containing compound metabolic process were enriched among down-regulated genes in JD19 and LH3 under salt stress (Figure 3E). KEGG enrichment analysis showed 
that the pathways of glycine, serine, and threonine metabolism, glutathione metabolism, pentose phosphate pathway, tryptophan metabolism were enriched in up-regulated DEGs in JD19 and LH3 (Figure 3F). Meanwhile, the pathways of caffeine metabolism, fructose and mannose metabolism, and plant hormone signal transduction were enriched in downregulated DEGs (Figure 3G).

A

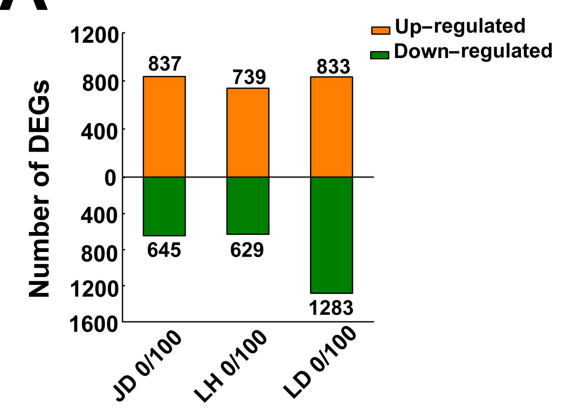

D
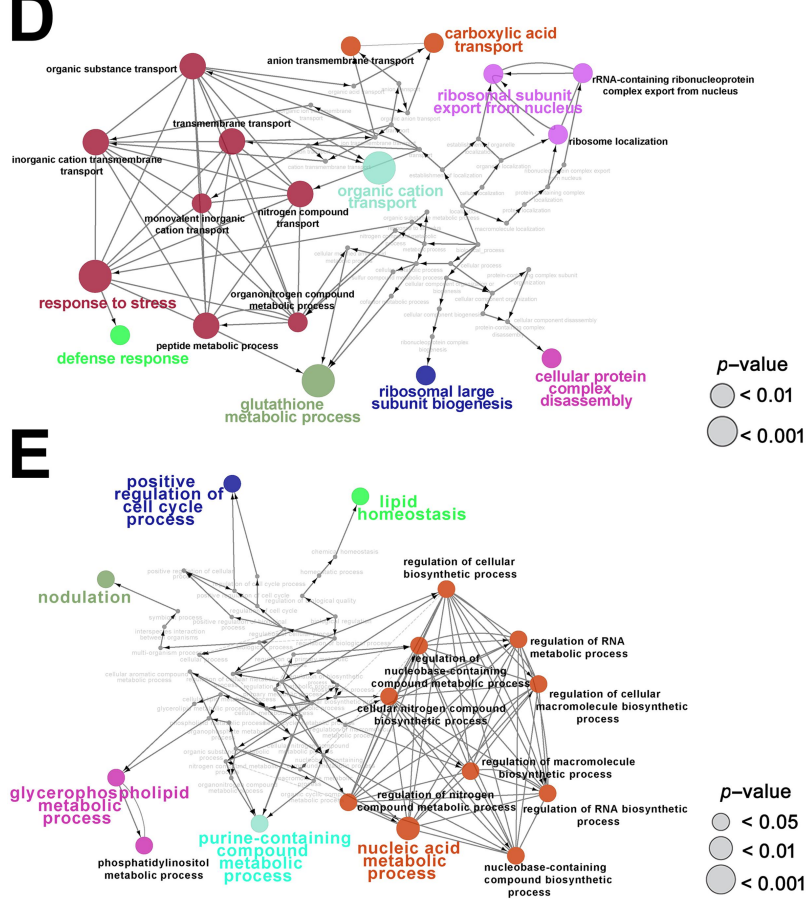

B

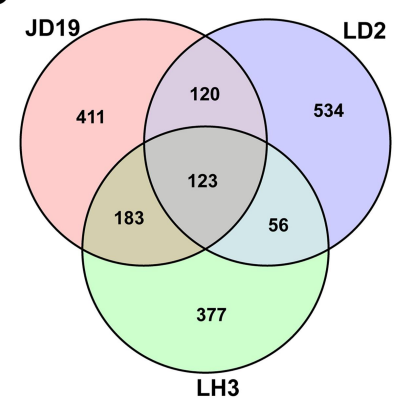

C

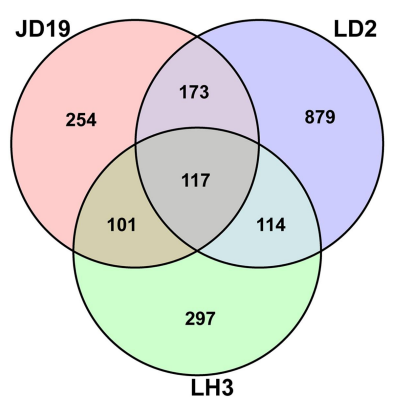

$\mathbf{F}$

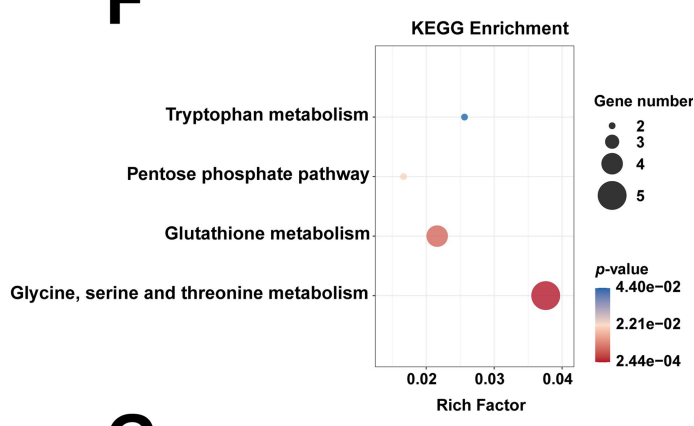

G

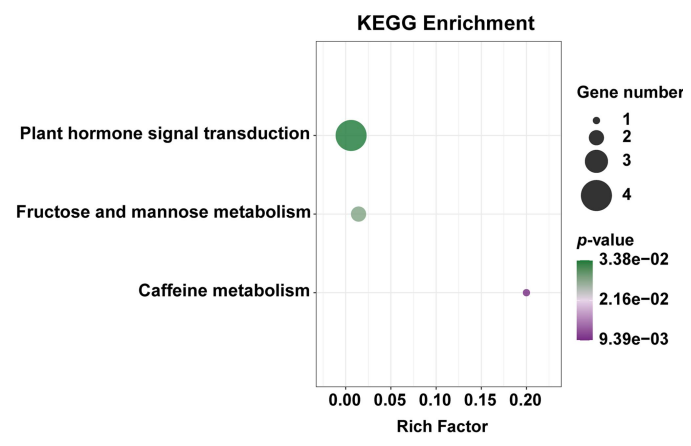

Figure 3. Transcriptome analysis of three soybean cultivars under $100 \mathrm{mM} \mathrm{NaCl}$ treatment. Statistics of DEGs (A), Venn diagram showing the overlapping and non-overlapping up-regulated DEGs (B), and down-regulated DEGs (C) among three soybean cultivars under $100 \mathrm{mM} \mathrm{NaCl}$ treatment. GO term of common up-regulated DEGs (D), and common down-regulated DEGs (E), KEGG pathway of commonly up-regulated DEGs (F), and common down-regulated DEGs (G) between JD19 and LH3 under $100 \mathrm{mM} \mathrm{NaCl}$ treatment. ClueGO analysis generated functionally grouped networks with GO terms as nodes linked based on their kappa score level $(\geq 0.4)$. Colors reflect the label of the most significant term per group. The node size represents the term enrichment significance.

In addition to the jointly regulated DEGs, we also found that JD19, LH3, and LD2 have some independently regulated DEGs under salt stress, which may be one of the reasons for the difference in salt tolerance among the three cultivars. During salt stress, a total of 411 genes were independently up-regulated, and 254 genes were down-regulated in JD19. Likewise in LH3 and LD2, there are 377 and 534 up-regulated genes and 297 and 879 down-regulated genes, respectively (Figure 3B,C). GO analysis revealed that JD19 independently up-regulated DEGs were enriched in biological processes related to oxalate metabolic process, carbon fixation, ribonucleoprotein complex assembly, organic anion 
transport. LH3 independently up-regulated DEGs were enriched in biological processes related to glycerol ether metabolic process, glycolipid transport, regulation of secretion, regulation of exocytosis. LD2 independently up-regulated DEGs were enriched in biological processes related to L-phenylalanine catabolic process, unsaturated fatty acid biosynthetic process, nitrogen fixation, mitochondrial respiratory chain complex assembly (Figure S4A). Moreover, JD19 independently down-regulated DEGs were enriched in biological processes related to cellular component biogenesis, sulfur compound catabolic process, glycolipid metabolic process. LH3 independently down-regulated DEGs were enriched in biological processes related to auxin efflux, auxin homeostasis, auxin polar transport. LD2 independently down-regulated DEGs were enriched in biological processes related to the regulation of jasmonic acid-mediated signaling pathway, hydrogen peroxide catabolic process, lipid homeostasis (Figure S4B). KEGG pathway enrichment analysis showed that JD19 independently up-regulated DEGs were enriched in a pathway related to lysine degradation, $\mathrm{ABC}$ transporters, circadian rhythm-plant, peroxisome, arginine, and proline metabolism. LH3 independently up-regulated DEGs were enriched in a pathway related to isoflavonoid biosynthesis, alanine, aspartate, and glutamate metabolism. LD2 independently up-regulated DEGs were enriched in a pathway related to taurine and typotaurine metabolism, pyruvate metabolism, and starch and sucrose metabolism (Figure S4C). Meanwhile, JD19 independently down-regulated DEGs were enriched in pathways related to base excision repair, tropine, piperidine and pyridine alkaloid biosynthesis, and isoquinoline alkaloid biosynthesis. LH3 independently down-regulated DEGs were enriched in pathways related to $\beta$-alanine metabolism, nitrogen metabolism, and regulation of autophagy. LD2 independently down-regulated DEGs were enriched in pathways related to arginine and proline metabolism, linoleic acid metabolism, valine, leucine, and isoleucine degradation (Figure S4D). The above results indicate that the salt-tolerant cultivars have both common pathways and unique pathways to deal with salt stress.

\subsection{Different Salt-Responsive Genes among JD19, LH3, and LD2}

Among the up-regulated DEGs, 18, 20, and 10 genes were annotated into glutathione metabolism and stress response-related metabolic processes in JD19, LH3, and LD2, which were mostly associated with response to salt stress (Figure $4 \mathrm{~A}$ ). Three DEGs were coexpressed in all cultivars, encoding glutathione S-transferase (GSTU37), small molecule heat shock protein (LOC100170732), and ascorbic acid peroxidase (LOC100792735). The expression of LOC100170732 and LOC100792735 were significantly increased in three soybean cultivars, while the expression of GSTU37 was decreased in LD2 but increased in JD19 and LH3 under salt stress (Figure 4A). Interestingly, we found that four genes, namely glutathione reductase (LOC100783766), CAT5, and late embryogenesis abundant proteins (LEA2 and LEA5), were significantly induced by salt stress in JD19 and LH3. In addition, five and seven genes encoding glutathione S-transferase were specifically expressed in JD19 and LH3, respectively (Figure 4A).

Under the salt stress condition, 15, 17, and 14 genes were annotated into multiple amino acid metabolism pathways in JD19, LH3, and LD2, respectively (Figure 4B). A total of $100 \mathrm{mM} \mathrm{NaCl}$ treatment inhibited ornithine decarboxylase (LOC548088) and proline dehydrogenase (PDH) genes, while asparagine synthase (AS2), serine hydroxymethyltransferase (LOC100499634), and glycine lyase (LOC100785811) genes were activated (Figure 4B). The hydroxymethyltransferase (SGT3), phosphoserine aminotransferase (LOC100795286), and glycine lyase (LOC100306654) genes were significantly upregulated only in JD19 and LH3. In addition, most of these DEGs were independently regulated in three cultivars under salt stress. For example, two genes, LOC100797464 and LOC100800978, encoding proline dehydrogenase were significantly down-regulated in JD19, while LOC100797583 and LOC100780526 encoding alanine glyoxylate aminotransferase were significantly up-regulated in LH3. The expression of glutamate synthase (LOC100789509, LOC100801991, LOC100812201, GDH1) and low specific L-threonine al- 
dolase (LOC100800811, LOC100790890) were significantly inhibited by salt stress in LD2 (Figure 4B).

A

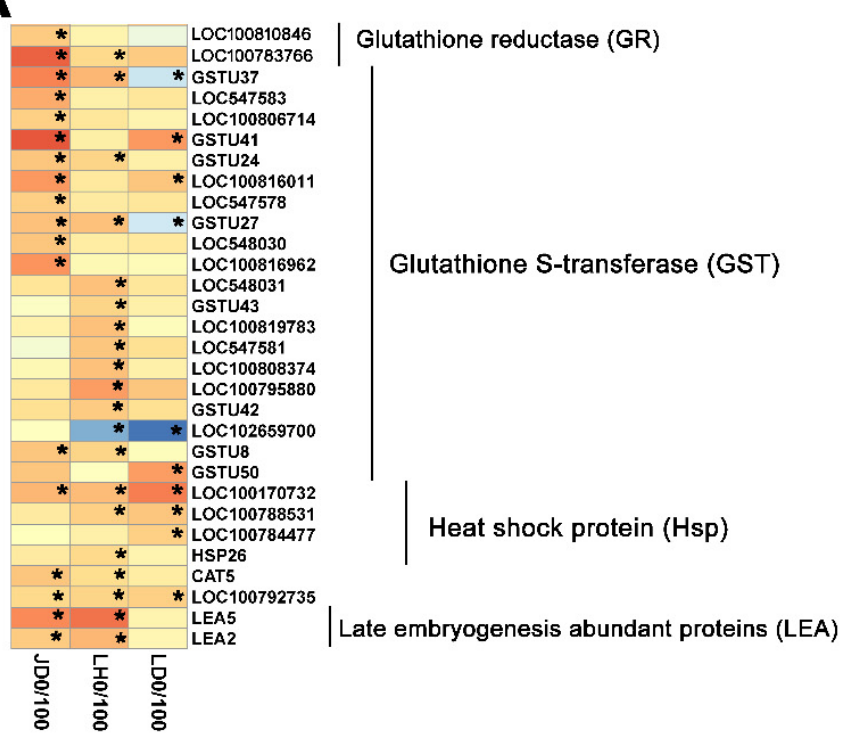

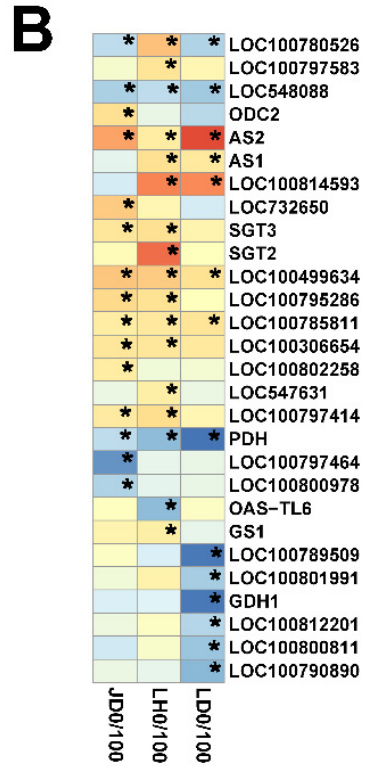

Figure 4. Heatmap of glutathione metabolism and stress response metabolism (A), amino acid metabolism (B)-related genes in three soybean cultivars under $100 \mathrm{mM} \mathrm{NaCl}$ treatment. Color panels display the $\mathrm{Log} 2$ fold change. Asterisks indicate the significant difference with an FDR $<0.01$ and fold change $\geq 2$.

\subsection{Metabolic Characteristics of Soybean Response to Salt Stress}

In order to explore alterations in major metabolic pathways in response to salt stress in different cultivars, we performed a metabolomic analysis. Principal component analysis (PCA) showed that the PC1 explained 15\% of the total variation, while the PC2 and PC3 explained $11 \%$ and $9.7 \%$ variation across the metabolites data, respectively (Figure 5A). The results indicated that there were obvious differences between the different treatment groups of the three soybean cultivars. Orthogonal projections to latent structures-discriminant (OPLS-DA) analysis was performed by screening out orthogonal variables unrelated to the classification variables. Through the analysis of non-orthogonal and orthogonal variables, reliable metabolic differences were obtained. The results showed that JD19, LH3, and LD2 were clearly separated under salt treatment, with all groups falling in the $95 \%$ confidence intervals (Hotelling's T-squared ellipse) (Figure 5B-D). Therefore, it was speculated that metabolic characteristics were significantly different among the three cultivars under salt stress. In the OPLS-DA model, $\mathrm{Q}^{2}$ (cum) was used to estimate the ability of prediction, and $R^{2} Y$ (cum) was used to estimate the "goodness of fit" of the model [27]. The results indicated that the test model was credible and repeatable.

\subsection{Differences in Metabolite Content among JD19, LH3, and LD2}

The identified differentially expressed metabolites (DEMs) were screened by variable importance in the VIP (VIP $>1)$ score and t-test $(p<0.05)$ based on the OPLS-DA model. In total, there were 14 DEMs in the three soybean cultivars under salt stress (Table S3). The heat map results indicated that all DEMs had obvious clustering, and the content of most compounds changed clearly under salinity stress in these cultivars (Figure 6A-C). Interestingly, the contents of oxproline, 4-aminobutyric acid, malonic acid, and beta-alanine were markedly increased in JD19 and LH3 under $100 \mathrm{mM} \mathrm{NaCl}$ treatment (Figure 6A,B). The content of tryptophan showed a trend of increase in LD2 (Figure 6C). Additionally, the levels of proline, citric acid, and threonine increased significantly in all cultivars. 

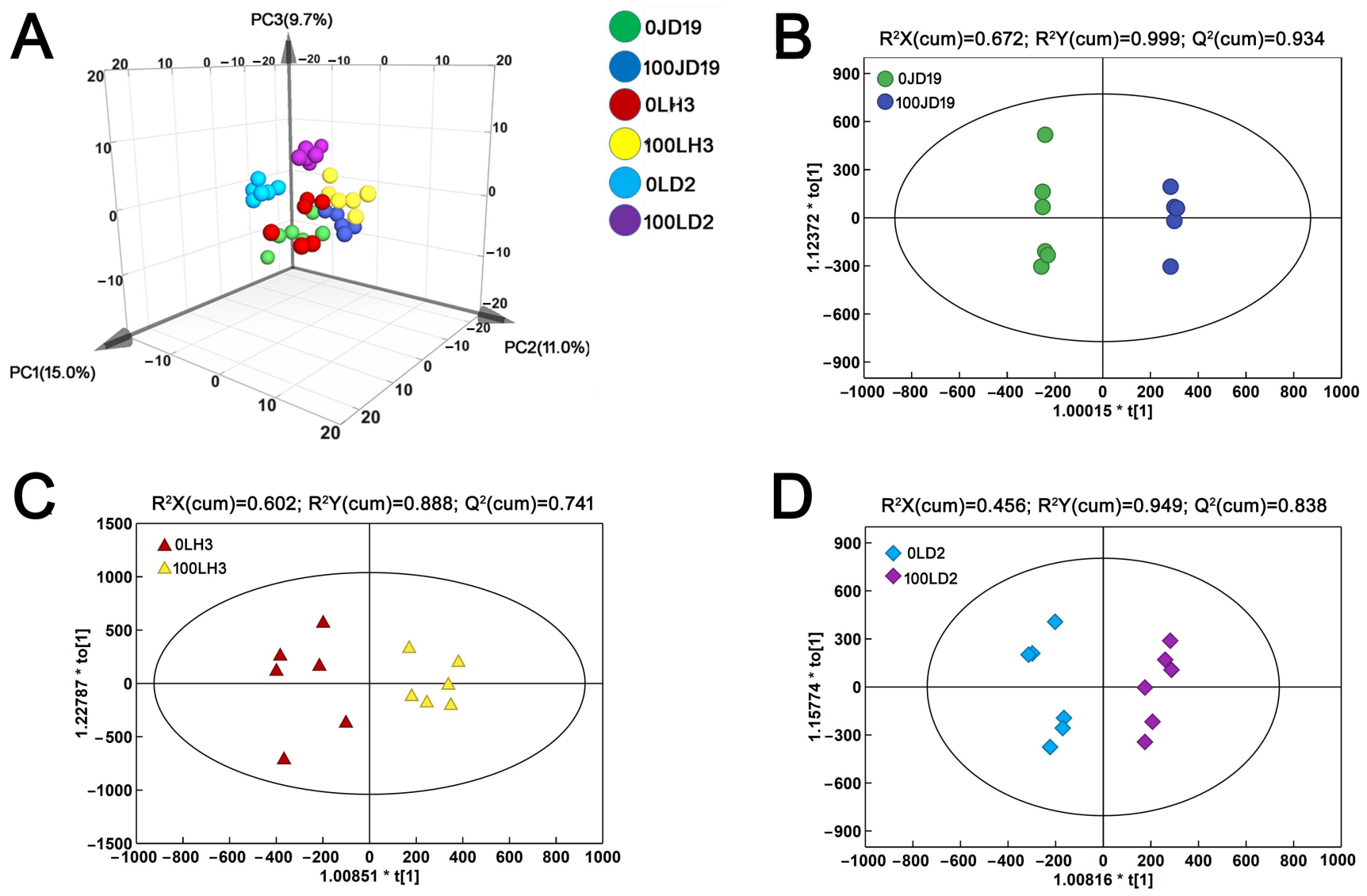

Figure 5. PCA diagram (A), and OPLS-DA scatter diagram of JD19 (B), LH3 (C), LD2 (D) under control and 100 mM $\mathrm{NaCl}$ treatment.

To further confirm the key metabolic pathways in three groups under salt treatment, we carried out an enrichment analysis of DEMs. The bubble plot results showed that there were 23, 27, and 32 metabolic pathways in JD19, LH3, and LD2, respectively (Figure 6D-F). In terms of $p$-value and impact, alanine, aspartate, glutamate metabolism, beta-alanine metabolism, and TCA cycle were the top three metabolic pathways in JD19 and LH3 (Figure 6D,E). TCA cycle, glycine, serine and threonine metabolism, glyoxylic acid, and dicarboxylic acid metabolism were key metabolic pathways in LD2 (Figure 6F). Together, these results suggested that amino acid metabolism and the TCA cycle were crucial pathways in response to salinity stress.

\subsection{Effects of Salt Stress on Amino Acid Contents and Nitrogen Metabolism for JD19, LH3, and $L D 2$}

To further verify the relationship between amino acid metabolism and salt stress, we examined free amino acid contents in all cultivars after salt treatment. The results showed that salt treatment induced a significant increase in the content of alanine, glutamine, proline, asparagine, and serine in JD19 and LH3. The content of tryptophan, tyrosine, and glutamate showed a similar increasing trend under the salinity stress condition in all three cultivars, while the content of lysine, isoleucine, and valine was decreased to different degrees (Figure 7A). 

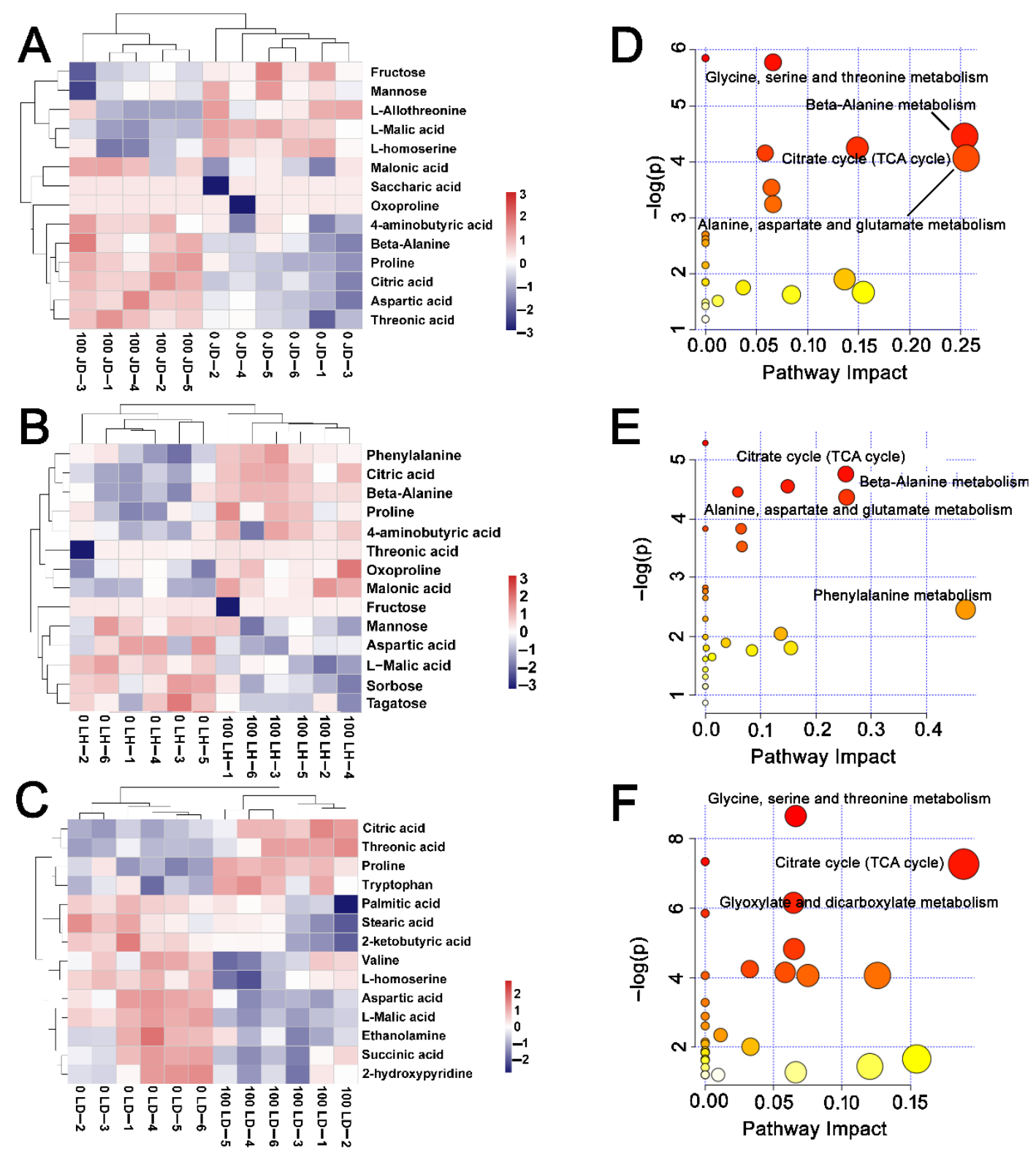

Figure 6. Heatmap clustering analysis of differentially expressed metabolites in (A) JD19, (B) LH3, (C) LD2, and KEGG pathway enrichment analysis in (D) JD19, (E) LH3, (F) LD2 under control and $100 \mathrm{mM} \mathrm{NaCl}$ treatment. Each bubble represents a metabolic pathway. The size of bubbles in abscissa represents the magnitude of the impact factor of the pathway in the topological analysis, with larger bubbles indicating higher impact factors. The bubble color in ordinate represents the $p$ values of the enrichment analysis, with darker color indicating a more significant enrichment degree.

Since amino acids are an important form of nitrogen $(\mathrm{N})$ in plants, we speculated that salt stress might affect $\mathrm{N}$ metabolism in three soybean cultivars. Plants obtain $\mathrm{N}$ mainly in the forms of nitrate $\left(\mathrm{NO}_{3}{ }^{-}\right)$and ammonium $\left(\mathrm{NH}_{4}{ }^{+}\right)$from the soil. After $\mathrm{NO}_{3}{ }^{-}$is transported into the cytoplasm by its transporters (NRT1 and NRT2), it is sequentially reduced to $\mathrm{NH}_{4}{ }^{+}$by nitrate reductase (NR) and nitrite reductase (NiR) $[28,29]$. However, the accumulation of $\mathrm{NH}_{4}{ }^{+}$is toxic to plant cells [30]. Thus, $\mathrm{NH}_{4}{ }^{+}$must be rapidly assimilated into amino acids by glutamine synthetase (GS) and glutamate synthase (GOGAT) $[28,29,31,32]$. We first analyzed the changes of $\mathrm{NO}_{3}{ }^{-}$and $\mathrm{NH}_{4}{ }^{+}$contents in three soybean cultivars under salt stress. A significant decrease in $\mathrm{NO}_{3}{ }^{-}$and an increase in $\mathrm{NH}_{4}{ }^{+}$were found in JD19, $\mathrm{LH} 3$, and LD2 under salt stress. However, the changes were different in the three cultivars. The $\mathrm{NO}_{3}{ }^{-}$content in JD19 and LH3 was $13.5 \%$ and $14.6 \%$, respectively, higher than that in LD2, while the $\mathrm{NH}_{4}{ }^{+}$content in JD19 and LH3 was $15.4 \%$ and $16.0 \%$, respectively, lower 
than that in LD2 (Figure 7B). Then, we determined the activities of nitrate reduction-related enzymes. Results showed that the NR activity exhibited little difference in JD19, LH3, and LD2 under the control condition. Although salt stress apparently inhibited the NR activity in three soybean cultivars, the effects of salt stress on NR activities in JD19 and LH3 were less severe than that in LD2 (Figure 7B). Similarly, $\mathrm{NaCl}$ treatment showed an inhibitory effect on NiR activity, which was decreased by $12.5 \%, 14.1 \%$, and $38.9 \%$ in JD19, LH3, and LD2, respectively (Figure 7B). Moreover, we also examined the activities of ammonia assimilation-related enzymes GS and GOGAT. Results showed that $\mathrm{NaCl}$ treatment significantly decreased the GS activity in three soybean cultivars. Relative to JD19 and LH3, the GS activity in LD2 roots decreased by 7.4\% (Figure 7B). In addition, the GOGAT activity was also decreased by $\mathrm{NaCl}$ treatment, but there was no obvious difference among the three cultivars (Figure 7B).

\section{A}

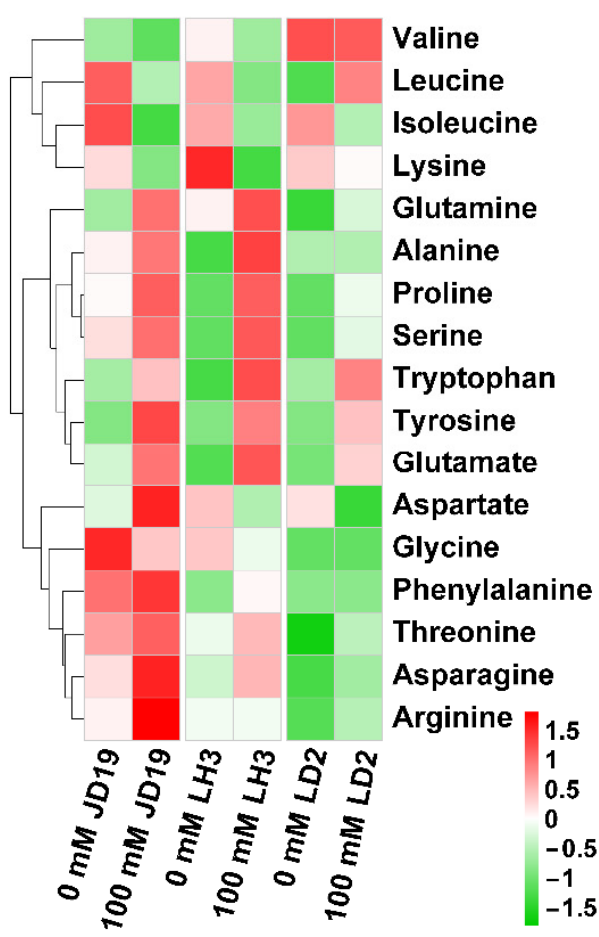

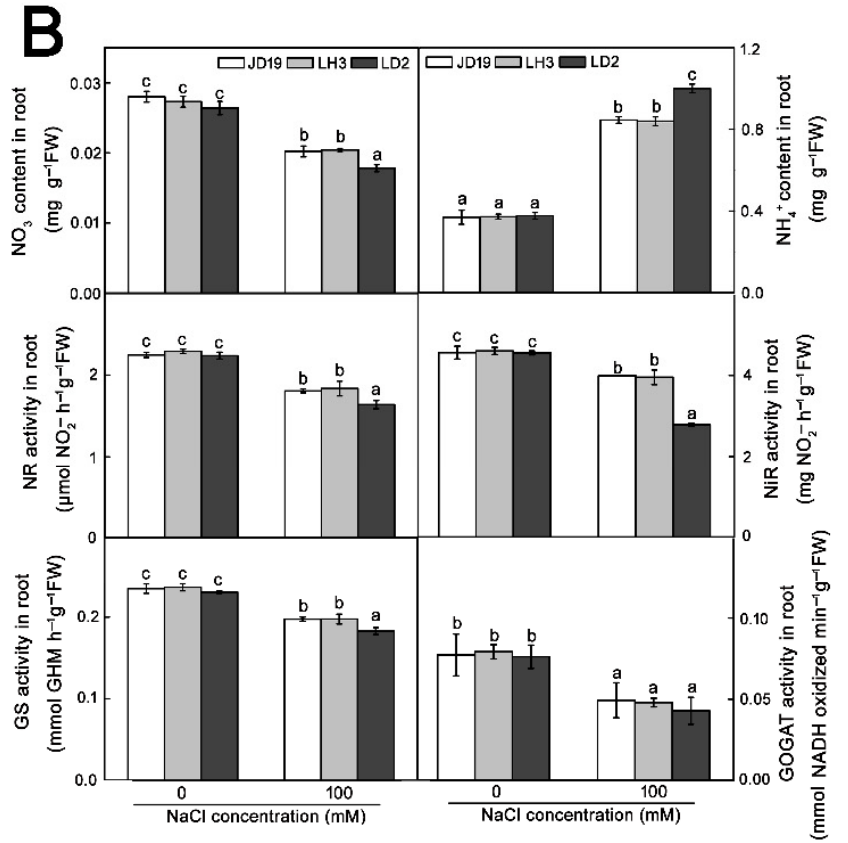

Figure 7. Effects of salt stress on free amino acid contents (A) and N metabolism-related enzymes activities (B) of three soybean cultivars. Data are means $\pm \mathrm{SE}(n=3)$. Different letters indicate significant difference at $p<0.05$.

Salt stress also affects the total $\mathrm{N}$ content in many plants [33,34]. Thus, we examined the $\mathrm{N}$ content in three soybean cultivars. Under the control condition, there was no significant difference among JD19, LH3, and LD2. However, $100 \mathrm{mM} \mathrm{NaCl}$ enhanced the $\mathrm{N}$ content in JD19 and LH3 but not in LD2. The N content in JD19 and LH3 under $100 \mathrm{mM}$ $\mathrm{NaCl}$ treatment was increased by $7.2 \%$ and $6.8 \%$, respectively (Figure $8 \mathrm{~A}$ ).

NUE has two components, $\mathrm{N}$ utilization efficiency (NUtE) and $\mathrm{N}$ uptake efficiency (NUpE). Plant NUE is affected by many physiological processes (N uptake, metabolism, assimilation, and allocation) and soil nutrient factors, such as soil $\mathrm{N}$ availability [28]. In order to explore whether JD19 and LH3 are more effective than LD2 in N uptake and utilization under salt stress, both NUpE and NUtE were analyzed. As shown in Figure 8B,C, JD19 and LH3 outperformed LD2 with respect to NUtE and NUpE under $100 \mathrm{mM} \mathrm{NaCl}$ treatment. Specifically, NUtE was decreased by $47.8 \%, 48.3 \%$, and $70.0 \%$ in JD19, LH3, and LD2, respectively (Figure 8B). Similarly, NUpE was decreased by $13.3 \%, 14.8 \%$, and $31.9 \%$ in JD19, LH3, and LD2, respectively (Figure 8C). However, under the control condition, there was no significant difference in NUtE and NUpE among the three cultivars. 


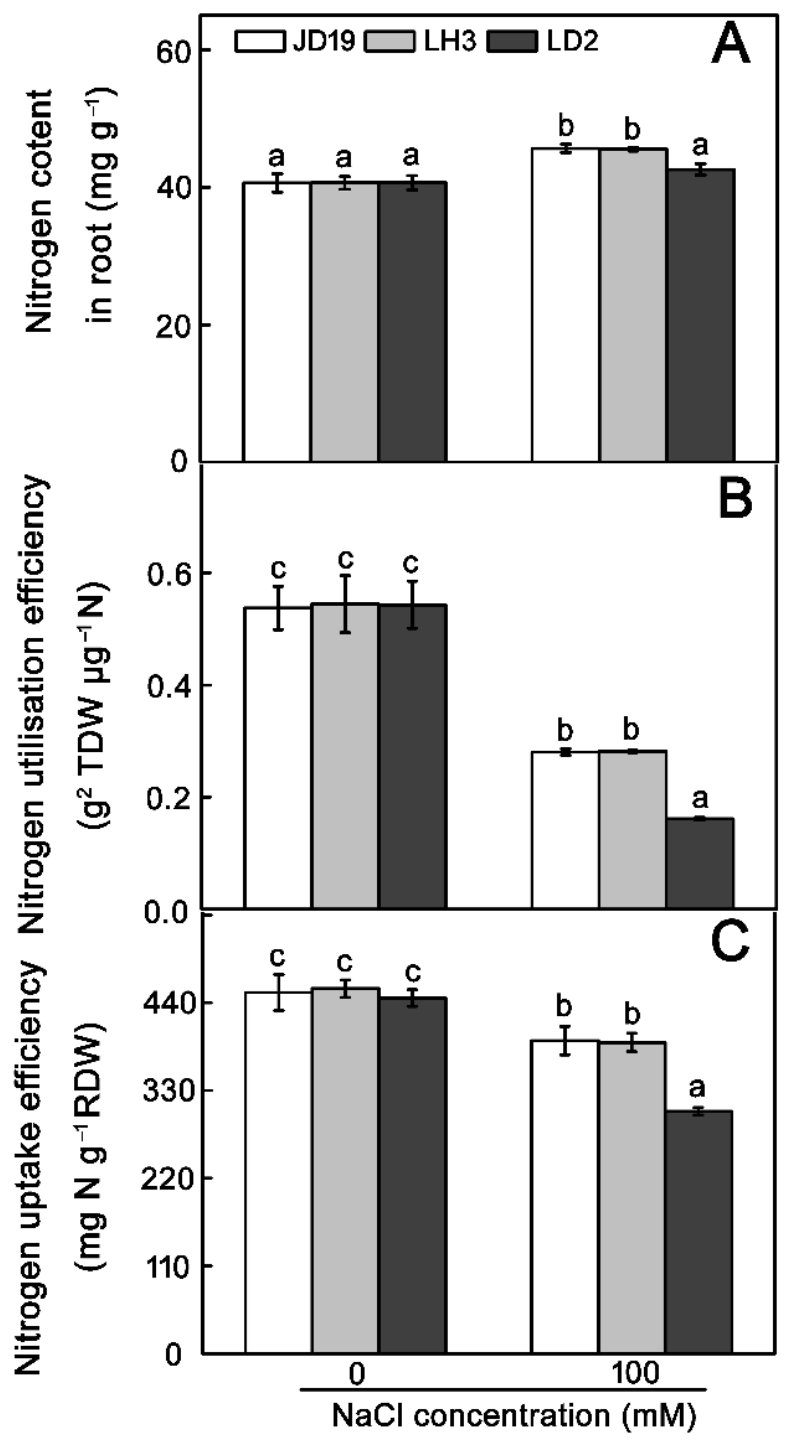

Figure 8. Effects of salt stress on $\mathrm{N}$ content (A), $\mathrm{N}$ utilization efficiency (B), and $\mathrm{N}$ uptake efficiency (C) of three soybean cultivars. TDW: total plant dry weight. RDW: root dry weight. Data are means \pm SE $(n=3)$. Different letters indicate significant difference at $p<0.05$.

\subsection{Effects of Salt Stress on Organic Acid Contents and TCA Cycle for JD19, LH3, and LD2}

The results of metabolome revealed that the TCA cycle was another important metabolic pathway of soybean in response to salt stress (Figure 6D-F). In order to further verify the relationship between the TCA cycle and salt tolerance of soybean, the activities of key enzymes involved in the TCA cycle and the contents of organic acid were determined. As shown in Figure 9, the activities of pyruvate dehydrogenase (PDH), citrate synthase (CS), aconitase (ACO), isocitrate dehydrogenase (IDH), $\alpha$-ketoglutarate dehydrogenase $(\alpha-\mathrm{KGDH})$, succinate dehydrogenase (SDH), and fumarase (Fum) were significantly reduced, but the malate dehydrogenase (MDH) activity was not influenced by salt stress (Figure 9B). In addition, the contents of $\alpha$-ketoglutarate, malate, fumarate, isocitrate, and succinate were decreased, while the content of citrate was increased under $100 \mathrm{mM} \mathrm{NaCl}$ treatment. Interestingly, the content of oxalacetate decreased in JD19 but increased in LH3 and LD2 (Figure 9A). 

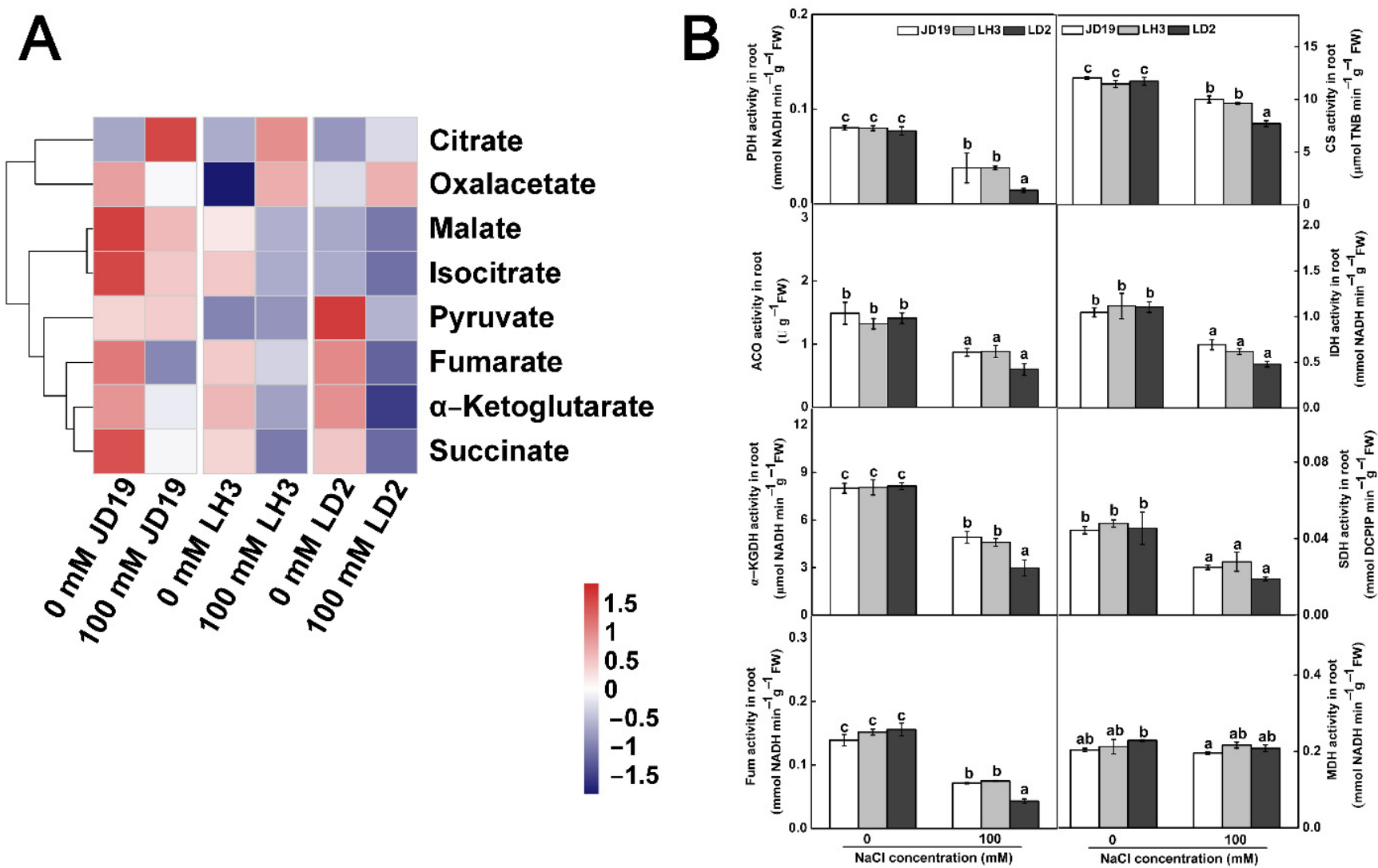

Figure 9. Effects of salt stress on organic acid contents (A) and TCA cycle-related enzymes activities (B) of three soybean cultivars. Data are means \pm SE $(n=3)$. Different letters indicate significant difference at $p<0.05$.

The TCA cycle is an important pathway of plant aerobic respiration. The intermediate products produced in the reaction process provide carbon $(C)$ skeleton, reducing power and ATP for plant growth and development. Under the salt stress condition, the contents of $\mathrm{NAD}^{+}$and $\mathrm{NADH}$ in three cultivars decreased in varying degrees. In LD2, the contents of $\mathrm{NAD}^{+}$and NADH obviously decreased by $13.0 \%$ and $29.7 \%$, respectively, resulting in the decrease in $\mathrm{NADH} / \mathrm{NAD}^{+}$ratio by $19.1 \%$ under salt stress. Meanwhile, the content of $\mathrm{NAD}^{+}$in JD19 and LH3 decreased by $21.6 \%$ and $21.2 \%$, respectively. The content of NADH decreased by $15.0 \%$ and $14.8 \%$, which led to a small $8.1 \%$ increase in the NADH/NAD ${ }^{+}$ ratio of JD19 and LH3 (Figure 10A-C). Combining the enzymatic analysis, the activity of the TCA cycle in JD19 and LH3 was higher than that of LD2 under salt stress. Moreover, NADH produced during the TCA cycle will be converted into ATP through the oxidative phosphorylation process for plant life activities. As shown in Figure 10D-F, salinity caused a significant decrease in ATP content, especially in LD2, but had little effect on ADP content in three cultivars, which led to a lower ATP/ADP ratio in LD2. Therefore, salt stress had a greater effect on ATP content and ATP/ADP ratio in LD2 compared with JD19 and LH3. 

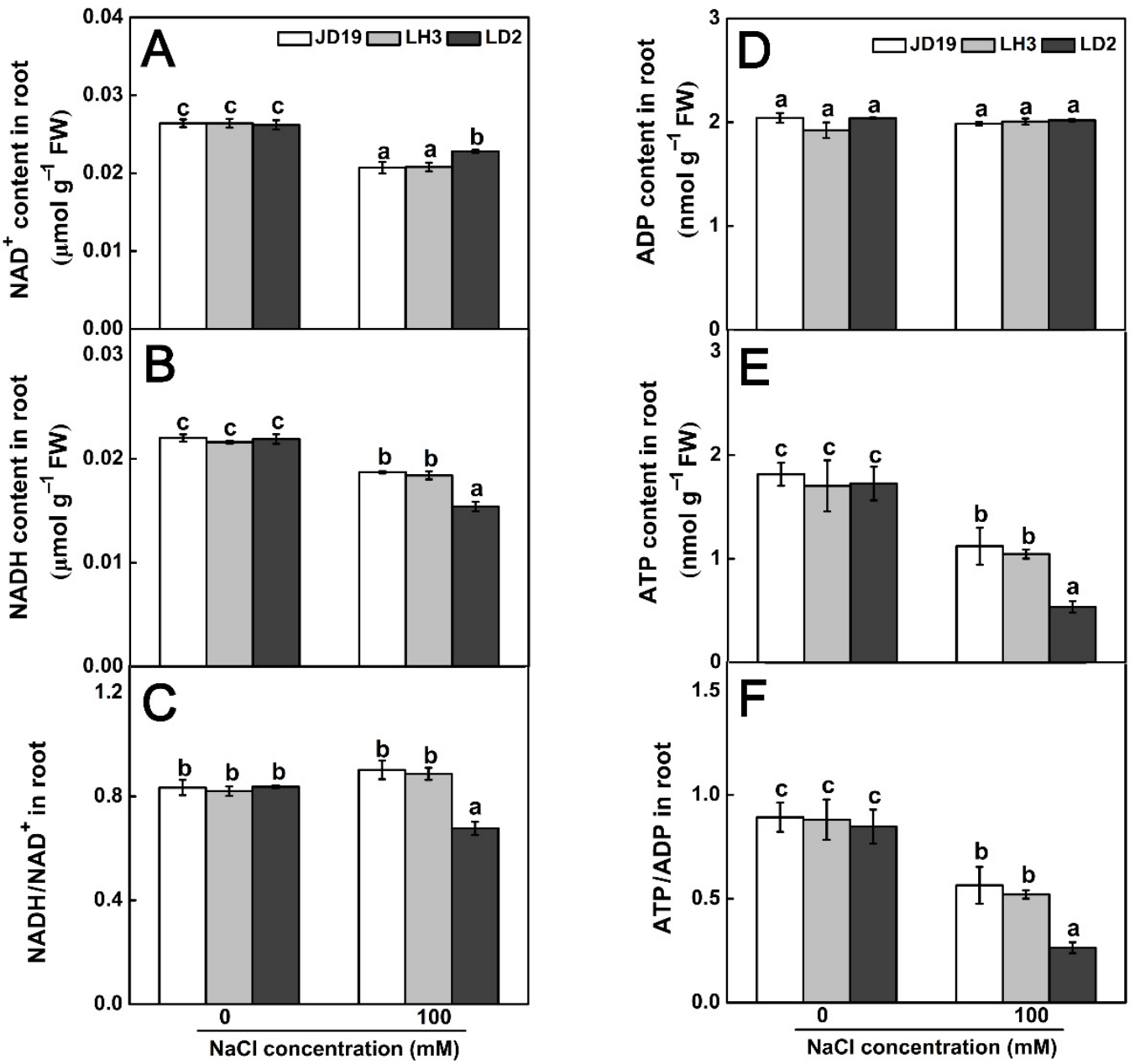

Figure 10. Effects of salt stress on $\mathrm{NAD}^{+}$content (A), NADH content (B), NADH/NAD ${ }^{+}$ratio (C), ADP content (D), ATP content $(\mathbf{E})$, and ATP/ADP ratio $(\mathbf{F})$ of three soybean cultivars. Data are means $\pm \mathrm{SE}(n=3)$. Different letters indicate significant difference at $p<0.05$.

\section{Discussion}

Salt stress affects plant growth and development, eventually causes a severe decrease in crop yield. Soybean is the main source of plant protein and lipid for humans. However, soybean growth is seriously affected by salt stress, especially in seedlings [35]. Thus, studying the responses of soybean seedlings to salt stress may provide significant insights into the mechanisms underlying soybean salt tolerance. In this study, three soybean cultivars, JD19, LH3, and LD2, were used for physiological, transcriptomic, and metabolic analyses to reveal the mechanism of short-term salt stress adaptability in soybean.

In our study, the greater primary root length, the more lateral roots, and the more biomass were observed in JD19 and LH3 relative to LD2 after $4 \mathrm{~d}$ of $100 \mathrm{mM} \mathrm{NaCl}$ treatment (Figure 1). These observations suggested that JD19 and LH3 may have an excellent adaptation to the saline condition than LD2. Because salt stress can rapidly produce a large number of ROS to damage plant cells, reducing the accumulation of ROS is one of the adaptive mechanisms for plants to improve salt stress resistance $[17,18]$. The activities of antioxidant enzymes (SOD, CAT, and APX) increased significantly in JD19 and LH3 under salt stress. In contrast, the contents of MDA and $\mathrm{H}_{2} \mathrm{O}_{2}$ increased by a smaller degree than those in LD2 (Figure S1). Similarly, RNA-seq results indicated that GmCAT5 is obviously up-regulated by salt stress in both JD19 and LH3 but not in LD2 (Figure 4A). Glutathione reductase (GR) are small molecule oxidoreductases that are involved in the process of defense against oxidative stress by directly scavenging ROS or redox regulating target proteins [36]. Under salt stress conditions, genes encoding GR were up-regulated in 
JD19 and LH3, indicating that they play a positive role in reducing cell oxidative damage caused by salt stress (Figure 4A). Similar studies have been reported in sesame, tomato, and Arabidopsis [37-39]. Moreover, some of the up-regulated DEGs were located in the pathway associated with glutathione metabolism. Glutathione S-transferase (GST), which participated in glutathione metabolism, is imperative in controlling redox balance and improving abiotic stress tolerance in plants [40]. In the current study, more GSTs were observed up-regulated in JD19 and LH3 under the saline condition, suggesting that the expression of GSTs was closely related to the salt resistance of soybean (Figure 4A).

Another major strategy for plants to enhance salt tolerance is to maintain ion homeostasis [18]. Many overlapped DEGs in JD19 and LH3 were involved in ion transmembrane transport processes, including organic cation transport, inorganic cation transmembrane transport, and transmembrane transport (Figure 3D). These processes contributed to reducing the intracellular ion accumulation caused by salinity and improving the stress tolerance of plants. Similarly, physiological data indicated JD19 and LH3 have lower contents of $\mathrm{Na}^{+}$ and $\mathrm{Cl}^{-}$, but higher content of $\mathrm{K}^{+}$than LD2 under salt stress (Figure 2). Therefore, JD19 and LH3 had a higher capacity of antioxidant and ion homeostasis maintenance compared with LD2 when they underwent salt stress conditions.

Salt stress also causes disorder of physiological processes such as photosynthesis, respiration, hormone action, and nutrition metabolism [18,41,42]. Many studies demonstrated that plant salt tolerance is closely related to various metabolic processes during plant growth and development [43-45]. In our study, JD19, LH3, and LD2 samples were separated clearly under the control and salt conditions based on PCA and OPLS-DA models (Figure 5). These results indicated that salt stress was the main reason for the difference in metabolite clustering. Interestingly, different metabolite enrichment results confirmed that salt stress-activated alanine, aspartate, glutamate metabolism, and beta-alanine metabolism are the top two metabolic pathways in JD19 and LH3 (Figure 6D-F). Similarly, genes commonly up-regulated by salt in JD19 and LH3 were also mapped to multiple amino acid metabolism pathways (Figure 4B). The above results suggested that amino acid metabolism played an important role in soybean response to salt stress.

Previous studies have been reported that amino acid metabolism is inextricably bound with abiotic stress tolerance [22,23]. Proline serves as an osmotic regulator involved in plant response to abiotic stresses. It also induces the expression of salt stress-responsive proteins to enhance the salt tolerance of Pancratium maritimum L [46]. In our study, the proline content was significantly higher in JD19 and LH3 than in LD2 under salt treatment. Similarly, the increase in alanine, asparagine, glutamine, and serine alleviated salt stress through osmotic adjustment in JD19 and LH3 (Figure 7A). Moreover, some amino acids, such as leucine, isoleucine, lysine, valine, and threonine, produce energy through catabolism to cope with environmental stresses [47]. Lysine, valine, leucine, and isoleucine degradation pathways have been identified as the key factors for drought tolerance in Arabidopsis [48]. Our study indicated that the contents of lysine, valine, and isoleucine were also decreased more in JD19 and LH3 than in LD2. The content of leucine showed a consistent decreasing trend in JD19 and LH3 but increased in LD2 (Figure 7A). Together, these results indicated that the greater ability of amino acid metabolism regulation in JD19 and LH3 might be correlated with osmotic adjustment and energy metabolism coping with salinity stress.

$\mathrm{N}$, one of the essential elements for plants, is the key component of nucleic acids, proteins, chlorophylls, and plant hormones $[49,50]$. It is well known that amino acids are an important form of organic $\mathrm{N}$ in plants. Asparagine and glutamine are involved in the primary and re-assimilation of $\mathrm{NH}_{4}{ }^{+}$[24]. Moreover, asparagine plays a major role in the long-distance transport of $\mathrm{N}$ and acts as an $\mathrm{N}$ storage pool in plants under adverse environments [51]. Therefore, changes in amino acids also reflect the changes in $\mathrm{N}$ metabolism in plants. On the one hand, plants could enhance the tolerance to salinity by increasing $\mathrm{N}$ acquisition [52]. Wang et al. [53] reported that the $\mathrm{NO}_{3}{ }^{-}$content was significantly increased in rice leaves under salt stress. Endophyte E. gansuensis increases 
the $\mathrm{NO}_{3}{ }^{-}$content in host plant Achnatherum inebrians compared with - E- plants (without endophyte) under $\mathrm{NaCl}$ stress [34]. In poplar and wheat, salt stress also increased the $\mathrm{NH}_{4}{ }^{+}$uptake $[54,55]$. Our present study showed that salt stress induced a more significant decrease in $\mathrm{NO}_{3}{ }^{-}$and increase in $\mathrm{NH}_{4}{ }^{+}$in LD2 than in JD19 and LH3 (Figure 7B). On the other hand, plants could enhance the tolerance to salinity by regulating the activity of $\mathrm{N}$ assimilation-related enzymes [53,56-58]. Surabhi et al. [59] reported that the decrease in $\mathrm{NR}$ and NiR activities was more significant in salt-sensitive mulberry than in salt-tolerant mulberry. Betti et al. [60] showed that GS plays an important role in abiotic stresses by increasing amino acid catabolism and producing protective $\mathrm{N}$ compounds. In JD19 and LH3, the activity of NR, NiR, and GS was higher than that in LD2 under salt treatment (Figure 7B). Thus, we speculated that the adaptive regulation of $\mathrm{N}$ metabolism might be one of the key mechanisms of salt tolerance in JD19 and LH3.

Salt stress has profound effects on nutrient contents, leading to nutrient metabolic disorders in plants [61]. In wild barley (Hordeum brevisubulatum), the $\mathrm{N}$ content is increased in roots as the $\mathrm{NaCl}$ concentration increases [62]. In this study, we also observed that salt stress increases the $\mathrm{N}$ content in the roots of JD19 and LH3 (Figure 8A). This may be because plant cells produce more ROS-scavenging enzymes under salt stress, and $\mathrm{N}$ is an essential component of all enzymes [63,64]. Plant NUE is a complex trait including NUpE and NUtE [28]. NUpE represents the capacity of a plant to obtain $\mathrm{N}$ from soil, which is closely correlated to the uptake of $\mathrm{NO}_{3}{ }^{-}$and the root structure. NUtE is more dependent on $\mathrm{N}$ assimilation and storage in plants [34]. As shown in this study, although salt stress affected the $\mathrm{N}$ uptake and assimilation to different degrees in the three soybean cultivars, the effect in JD19 and LH3 was less severe than that in LD2 (Figure 8B,C). Therefore, the high $\mathrm{N}$ content and NUE is one of the adaptive strategies in JD19 and LH3 for salt stress.

TCA cycle was another crucial metabolic pathway among three cultivars under salt stress (Figure 6D-F). In this study, the contents of most organic acid, including TCA cycle intermediates $\alpha$-ketoglutarate, malate, fumarate, isocitrate, and succinate, showed downward trends under $100 \mathrm{mM} \mathrm{NaCl}$ treatment in three soybean cultivars (Figure 9A). Consistent with this, the activities of most enzymes involved in the catalytic process of the TCA cycle decreased significantly under salt stress (Figure 9B). The reduction in organic acid, especially TCA cycle intermediates, might be due to the decrease in TCA cycle activity and the increase in the demand for osmotic regulation compounds to deal with salt stress [65]. Similar results have also been reported in halophytes, such as Thellungiella halophile [65], Suaeda salsa [66], and Chenopodium quinoa [67]. In addition, the metabolic phenotype of organic acid reduction implied the decrease in $C$ flow from glycolysis (EMP) to the TCA cycle, resulting in the decrease in TCA cycle activity and ultimately reducing the production of NADH and ATP [68]. We found that the content of NADH significantly decreased by salt stress, especially in LD2, which led to the lower ratio of $\mathrm{NADH} / \mathrm{NAD}^{+}$in $\mathrm{LD} 2$ (Figure $10 \mathrm{~A}-\mathrm{C}$ ). In general, the $\mathrm{NADH} / \mathrm{NAD}^{+}$ratio was used to evaluate the strength of the TCA cycle [69]. Therefore, the higher ratio of $\mathrm{NADH} / \mathrm{NAD}^{+}$in JD19 and LH3 indicated the higher TCA cycle activity under salt stress, which promoted the regeneration of $\mathrm{NAD}^{+}$and then entered the next cycle. Subsequently, NADH produced by EMP and TCA cycle will be further transformed into ATP through respiratory electron transfer and oxidative phosphorylation for plant life activities. Li et al. [70] found that salt stress could inhibit the TCA cycle and significantly reduce ATP production in cucumber seedlings. In our study, salt stress had less effect on ATP content in JD19 and LH3 compared with LD2 (Figure 10E). Previous studies have shown that the decrease in TCA cycle activity and reducing power might be related to the decrease in plant growth rate under salt stress [45,71]. Physiological results also showed that the inhibitory effect of $100 \mathrm{mM} \mathrm{NaCl}$ treatment on root growth of LD2 was significantly stronger than that of JD19 and LH3 (Figure 1). Therefore, the regulation of organic acid metabolism and the TCA cycle was closely related to growth inhibition, which might be an energy-saving strategy for JD19 and LH3 under the saline condition. In addition, oxaloacetate is an important TCA cycle intermediate product produced by the transamination of aspartate, which can enter the 
next cycle [72]. In LH3 and LD2, the level of oxaloacetate increased with the salinity concentration, accompanied by the decrease in aspartate content. The results indicated that the increase in oxaloacetate level caused by salt stress might be due to the enhanced transamination of aspartate.

\section{Materials and Methods}

\subsection{Plant Materials, Growth Conditions, and $\mathrm{NaCl}$ Treatments}

The three soybean cultivars, JINDOU 19 (JD19), LONGHUANG 3 (LH3), LONGDOU 2 (LD2), have similar growth periods (Table S4). JD19 and LH3 have large seeds and lodging resistance. LD2 was bred in 2005, with 4-5 branches and small seeds. Seeds of these cultivars were provided by Professor Guohong Zhang at Gansu Academy of Agricultural Sciences, Lanzhou, Gansu, China. The seeds were sterilized with $1 \% \mathrm{NaClO}$ for $5 \mathrm{~min}$ and $2 \% \mathrm{H}_{2} \mathrm{O}_{2}$ for $20 \mathrm{~min}$, respectively. Then, they were washed with sterile water and germinated on an aseptic sponge and gauze for $48 \mathrm{~h}$ at $28^{\circ} \mathrm{C}$ in the dark. The germinated seeds were transferred to $300 \mathrm{~mL}$ hydroponic pots and grown in 1/4-strength Hoagland liquid medium ( $\mathrm{pH}$ 6.0) for $2 \mathrm{~d}$. The soybean seedlings with $3 \mathrm{~cm}$ roots were selected and transplanted to 1/4-strength Hoagland solution with or without $100 \mathrm{mM} \mathrm{NaCl}$ for $4 \mathrm{~d}$. The solution was replaced every day. The plants were cultured in a $25^{\circ} \mathrm{C}$ greenhouse with a light/dark period of $16 / 8 \mathrm{~h}$ under $300 \mu \mathrm{mol} \mathrm{m}^{-2} \mathrm{~s}^{-1}$ photon flux density. After treatment for $4 \mathrm{~d}$, roots were immediately used for analysis. The seedling roots were photographed with a Nikon digital camera, and the primary root length and lateral root numbers were analyzed using the Image J software. More than 15 seedlings per cultivar were analyzed $(n=15)$.

\subsection{Determination of $\mathrm{MDA}$ and $\mathrm{H}_{2} \mathrm{O}_{2}$ Content and the Activities of Antioxidant Enzymes}

The MDA content was determined according to the method of Hodges et al. [73]. A total of $0.5 \mathrm{~g}$ of soybean roots were extracted in $10 \%$ TCA (trichloroacetic acid) at $4{ }^{\circ} \mathrm{C}$. After centrifugation for $10 \mathrm{~min}$ at $4000 \times \mathrm{g}$, the supernatant was incubated for $1 \mathrm{~h}$ with the same amount of $0.5 \%$ TCA at $95{ }^{\circ} \mathrm{C}$. Then the absorbance was measured at 440,535 , and $600 \mathrm{~nm}$. The $\mathrm{H}_{2} \mathrm{O}_{2}$ content was measured according to the method of Yang et al. [74]. A total of $0.5 \mathrm{~g}$ of root tissues were extracted with $2 \mathrm{~mL}$ of cooled $0.1 \%$ TCA. After centrifugation for $20 \mathrm{~min}$ at $12,000 \times g$ at $4{ }^{\circ} \mathrm{C}$, the supernatant was incubated with $1 \mathrm{~mL}$ of $1 \mathrm{M} \mathrm{KI}$ and $0.5 \mathrm{~mL}$ of $0.1 \mathrm{M}$ Tris- $\mathrm{HCl}(\mathrm{pH} 7.6)$ for $1 \mathrm{~h}$ in the dark. Then the absorbance was immediately measured at $390 \mathrm{~nm}$. The activity of SOD, POD, CAT, and APX was determined as previously described [74]. In each independent assay, $0.5 \mathrm{~g}$ of samples were used in each replicate.

\subsection{Total RNA Extraction and qRT-PCR Analysis}

The total RNA was extracted from soybean roots using a Plant RNA Extraction Kit (Thermo Fisher). The cDNA was synthesized from total RNA $(1 \mu \mathrm{g})$ using the PrimeScript RT Reagent Kit (Thermo Fisher, Waltham, MA, USA), and qRT-PCR was performed using the SYBR PrimeScript RT-PCR Kit (Thermo Fisher, Waltham, MA, USA). The GmACTIN2 was used as the internal control. Fold changes $\left(2^{-\Delta \Delta C t}\right)$ were expressed relative to the control. The primer sequences used in this study are listed in Table S5.

\subsection{Transcript Profiling}

Root tissues were sampled from the three soybean cultivars subjected to control and $100 \mathrm{mM} \mathrm{NaCl}$ treatment mentioned above and were frozen rapidly with liquid nitrogen. There were three replicates per group for RNA-seq experiments. The RNA extraction, cDNA library construction, sequencing, and quality control were carried out according to the method of Yang et al. [75]. The sequence alignment was based on the NCBI database of soybean (https:/ / www.ncbi.nlm.nih.gov/genome/term=txid3847[orgn] (accessed on 5 November 2021)) using Hisat2 tools soft [76]. Gene expression was calculated by the FPKM (Fragments per kilobase of transcript per million fragments mapped) algorithm [77]. The differentially expressed genes (DEGs) were screened with FDR 
(false discovery rate) $<0.05$ and fold change $\geq 2$. Enrichment analyses of Gene Ontology (GO) based on the DEGs were performed by using the ClueGO plugin in Cytoscape [78]. KEGG (Kyoto encyclopedia of genes and genomes) pathway and GO enrichment analyses were based on $p$-value $<0.05$.

\subsection{Metabolite Extraction and GC-TOF-MS Analysis}

About $0.01 \mathrm{~g}$ of frozen root tissues were used for metabolite extraction. Samples were extracted in $450 \mu \mathrm{L}$ of pre-cooled methanol containing $10 \mu \mathrm{L}$ of adonitol $(0.5 \mathrm{mg} / \mathrm{mL})$ as an internal standard. After vortex mixing for $30 \mathrm{~s}$, samples were ground with a ball mill $(35 \mathrm{~Hz}$ ) for $4 \mathrm{~min}$, followed by ultrasound exposure for $5 \mathrm{~min}$ in an icy water bath, and centrifuged at $4{ }^{\circ} \mathrm{C}$ for $15 \mathrm{~min}$ at $12,000 \mathrm{rpm}$. After dried under vacuum, the extracted samples were incubated with $60 \mu \mathrm{L}$ of methoxyamination hydrochloride $(20 \mathrm{mg} / \mathrm{mL}$ in pyridine) for $30 \mathrm{~min}$ at $80^{\circ} \mathrm{C}$, and then derivatized with $80 \mu \mathrm{L} \mathrm{N}$, O-Bis (trimethylsilyl) trifluoroacetamide (BSTFA) for $1.5 \mathrm{~h}$ at $70^{\circ} \mathrm{C}$. Subsequently, metabolite compounds were analyzed using gas chromatography (Agilent 7890, Santa Clara, CA, USA) coupled with a time-of-flight mass spectrometer (GC-TOF-MS, LECO Chroma TOF Pegasus HT, Silver Spring, MD, USA). Chroma TOF (V4.3x, LECO, Silver Spring, MD, USA) software and the LECO-Fiehn Rtx5 database were used for raw data analysis [79,80].

\subsection{Determination of $N$ and Ion Contents}

The total N content was measured using flow injection analysis (FIAstar 5000 Analyzer, FOSS, Höganäs, Sweden) with $0.1 \mathrm{~g}$ of dry powdered samples. Additionally, $\mathrm{N}$ utilization efficiency (NUtE) and N uptake efficiency (NUpE) were calculated according to the method of Wang et al. [81]. Briefly, NUtE was calculated as the total plant dry weight divided by $\mathrm{N}$ concentration $\left(\mathrm{g}^{2} \mathrm{TDW} \mathrm{mg}^{-1} \mathrm{~N}\right.$ ). $\mathrm{NUpE}$ was calculated as the total $\mathrm{N}$ accumulation divided by root dry weight ( $\left.\mathrm{mg} \mathrm{N} \mathrm{g}^{-1} \mathrm{RDW}\right)$. Dry samples $(0.1 \mathrm{~g})$ were used for the determination of ion contents. The $\mathrm{Na}^{+}$and $\mathrm{K}^{+}$contents were determined by the method of Chen et al. [33]. The $\mathrm{Cl}^{-}$content was determined by the method of $\mathrm{Li}$ et al. [82].

\subsection{Determination of Amino Acid and Organic Acid Contents}

Amino acid contents were measured using the previously reported method [80]. Briefly, $0.1 \mathrm{~g}$ (dry weight) of soybean roots were extracted with $0.5 \mathrm{M} \mathrm{HCl}$ and vortexed at $8000 \mathrm{rpm}$ for $20 \mathrm{~min}$. After sonication in a water bath at $25^{\circ} \mathrm{C}$ for $20 \mathrm{~min}$, the samples were centrifuged at $20,000 \times g$ for $20 \mathrm{~min}$. Finally, the supernatant was transferred to a liquid chromatographic sample bottle, added to ISTD, and then diluted to $1 \mathrm{~mL}$ with $80 \%$ acetonitrile aqueous solution (LC/MS). Hydrophilic interaction chromatography (HILIC) was used to separate amino acids (Agilent InfinityLab Poroshell 120 HILIC-Z). The concentrations of amino acids were measured by the comparison of peaks and retention times with corresponding standards (Sigma-Aldrich, Saint Louis, MO, USA). Organic acid contents were determined according to the method of Coelho et al. [83] with minor modifications. A total of $0.1 \mathrm{~g}$ (dry weight) soybean roots were extracted with $1.5 \mathrm{~mL}$ ultrapure water. After vortex mixing for $20 \mathrm{~min}$, the samples were sonicated in a water bath at $25^{\circ} \mathrm{C}$ for $50 \mathrm{~min}$ and then centrifuged at $6000 \times \mathrm{g}$ for $6 \mathrm{~min}$. A total of $1 \mathrm{~mL}$ of supernatant for $0.22 \mu \mathrm{M}$ water phase filter membrane was put into the liquid chromatography injection bottle, and the contents of organic acid in the sample were determined by high-performance liquid chromatography (HPLC) (EMpower3 2998 AcQuITY Arc, Boston, MA, USA).

\subsection{Determination of $\mathrm{NO}_{3}{ }^{-}$and $\mathrm{NH}_{4}{ }^{+}$Contents and Activities of $\mathrm{N}$ Metabolism-Related Enzymes}

$0.5 \mathrm{~g}$ of soybean roots were used for the determination of $\mathrm{NO}_{3}{ }^{-}$and $\mathrm{NH}_{4}{ }^{+}$contents and activities of $\mathrm{N}$ metabolism-related enzymes. The $\mathrm{NO}_{3}{ }^{-}$and $\mathrm{NH}_{4}{ }^{+}$contents were determined following the method of Wang et al. [81]. The activity of NR was determined according to the method of Du et al. [84]. Soybean roots were extracted in an enzyme extraction buffer (100 mM Hepes-KOH (pH 7.5), 7 mM cysteine, $3 \%$ PVPP and $1 \mathrm{mM}$ EDTA). 
NiR was extracted in an enzyme extraction buffer (50 mM PBS buffer (pH 8.8), 1 mM EDTA, $3 \%(w / v)$ bovine serum albumin and $25 \mathrm{mM}$ cystein). The NiR activity was determined spectrophotometrically following the procedure of Wang et al. [81]. GS was extracted with the enzyme extraction buffer ( $50 \mathrm{mM}$ Tris- $\mathrm{HCl}(\mathrm{pH} 8.0), 400 \mathrm{mM}$ sucrose, $2 \mathrm{mM}$ DTT, and $2 \mathrm{mM} \mathrm{MgSO}_{4}$ ), and the GS activity was determined according to the method of Wang et al. [81]. For determination of the activity of NADH-GOGAT, root tissues were extracted in an extraction buffer (100 mM Tris- $\mathrm{HCl}$ ( $\mathrm{pH} 7.6), 1 \mathrm{mM}$ EDTA, $1 \mathrm{mM} \mathrm{MgCl} 26 \mathrm{H}_{2} \mathrm{O}$ and $10 \mathrm{mM} \beta$-Mercaptoethanol), and then centrifuged at $12,000 \times \mathrm{g}$ for $20 \mathrm{~min}$ at $4{ }^{\circ} \mathrm{C}$. The supernatant was used for the determination of NADH-GOGAT. NADH-GOGAT activity was determined following the method of Singh et al. [85]. The reaction buffer $(100 \mathrm{mM}$ $\alpha$-ketoglutaric acid, $25 \mathrm{mM}$ Tris- $\mathrm{HCl}(\mathrm{pH} \mathrm{7.6})$ and $10 \mathrm{mM} \mathrm{KCl}$ ) was preheated to $30^{\circ} \mathrm{C}$ in a water bath and then sequentially mixed with $0.9 \mathrm{~mL}$ of reaction solution buffer, $0.1 \mathrm{~mL}$ of $3 \mathrm{mM} \mathrm{NADH}, 0.5 \mathrm{~mL}$ of crude enzyme extract and $0.4 \mathrm{~mL}$ of $20 \mathrm{mM}$ glutamine. The absorbance change of the mixture at $340 \mathrm{~nm}$ was measured and recorded within $3 \mathrm{~min}$.

\subsection{Determination of $N A D^{+}, N A D H, A D P, A T P$ Contents, and Enzyme Activities Related to TCA Cycle}

$0.5 \mathrm{~g}$ of soybean roots were used for the determination of $\mathrm{NAD}^{+}, \mathrm{NADH}, \mathrm{ADP}, \mathrm{ATP}$ contents, and enzyme activities related to the TCA cycle. The NAD ${ }^{+}$and NADH contents were determined following the method of Wang et al. [86]. ADP and ATP contents were assayed using ELISA kits (Shanghai Jiwei Biological Technology Co., Ltd., Shanghai, China) according to the method as described by the manufacturer's instructions.

PDH activity was determined according to the method of Millar et al. [87]. Root samples were extracted in an enzyme extraction buffer $(80 \mathrm{mM}$ tetrasodium pyrophosphate (pH 7.5), $0.3 \mathrm{M}$ mannitol, $10 \mathrm{mM} \mathrm{K}{ }_{3} \mathrm{PO}_{4}, 25 \mathrm{mM}$ cysteine, $2 \mathrm{mM}$ EGTA, $1 \%$ PVP and $1 \%$ BSA). After centrifugation $2000 \times g$ for $5 \mathrm{~min}$, the supernatant was obtained and continued centrifuged $15,000 \times g$ for $20 \mathrm{~min}$, then resuspended the precipitation with $1 \mathrm{~mL}$ of resuspension buffer (10 mM TES- $\mathrm{KOH}$ (pH 7.5), $0.3 \mathrm{M}$ mannitol, and $0.1 \% \mathrm{BSA})$. After centrifugation at $30,000 \times g$ for $45 \mathrm{~min}$, the supernatant was the crude enzyme solution of PDH. To determinate the PDH activity, a $100 \mu \mathrm{L}$ crude enzyme solution was added to the reaction buffer (75 mM Hepes- $\mathrm{NaOH}(\mathrm{pH} 7.5), 10 \mathrm{mM} \mathrm{NAD}^{+}, 10 \mathrm{mM} \mathrm{MgCl} 2,10 \mathrm{mM}$ cysteine, $0.2 \mathrm{mM} \mathrm{CoA}, 2 \mathrm{mM}$ thiamine pyrophosphate) and incubated at $25^{\circ} \mathrm{C}$ for $15 \mathrm{~min}$. After the $20 \mathrm{mM}$, sodium pyruvate was added, the changes of absorbance value at $340 \mathrm{~nm}$ within 3 min were recorded. The activities of CS, IDH, Fum, and MDH were determined according to the method of Jenner et al. [88]. $\alpha-\mathrm{KGDH}$ was performed according to the method of Pekovich et al. [89]. Root samples were extracted in an enzyme extraction buffer containing $20 \mathrm{mM}$ Tris-HCl (pH 7.5), $1 \mathrm{mM}$ EDTA, $1 \mathrm{mM} \mathrm{DTT,} 0.2 \mathrm{mM}$ PMSF, $0.01 \%$ Triton $\mathrm{X}-100$ and $0.02 \%$ sodium deoxycholate. After centrifugation at $10,000 \times g$ for $10 \mathrm{~min}$ at $4{ }^{\circ} \mathrm{C}$, the supernatant was used for the determination of $\alpha-\mathrm{KGDH}$. The $\alpha-\mathrm{KGDH}$ activity was determined following the method of Pekovich et al. [89]. Briefly, a $400 \mu \mathrm{L}$ crude enzyme solution was added to the reaction buffer (50 mM MOPS (pH 8.0), $10 \mathrm{mM} \mathrm{NAD}^{+}$, $2 \mathrm{mM} \mathrm{MgCl}_{2}, 0.16 \mathrm{mM} \mathrm{CoA}, 1.2 \mathrm{mM} \mathrm{CaCl}_{2}, 0.04 \mathrm{mM}$ rotenone and $0.5 \%$ Triton X-100) and incubated at $25{ }^{\circ} \mathrm{C}$ for $15 \mathrm{~min}$. After the $20 \mathrm{mM} \alpha$-ketoglutarate was added, the changes of absorbance value at $340 \mathrm{~nm}$ within $3 \mathrm{~min}$ were recorded. SDH was determined following the method of Schirawski and Unden [90].

\subsection{Statistics Analysis}

For statistical analysis of metabolites, five JD19 biological samples under $100 \mathrm{mM} \mathrm{NaCl}$ treatment and six other biological samples, including JD19, LH3, and LD2 with or without $100 \mathrm{mM} \mathrm{NaCl}$ treatment, were used separately. PCA and OPLS-DA were performed using the SIMCA software (version 15.0.2). Differentially expressed metabolites were identified using Student's t-test $(p<0.05)$ and VIP (VIP $>1)$ based on the weighted sum of the squares of the OPLS-DA. The metabolic pathways were determined by MetaboAnalyst (http://metaboanalyst.ca/ (accessed on 5 November 2021)) based on the significantly differential metabolites. Heat map, amino acid, and organic acid cluster analysis were 
generated by $\mathrm{R}$ (version 3.2.2). Physiological data analyses were performed with SPSS 17.0, and statistical analyses were conducted with one-way ANOVA followed by Duncan's multiple range test $(p<0.05)$. Each experiment was repeated at least three times. The values were expressed as mean $\pm \mathrm{SE}$.

\title{
5. Conclusions
}

In summary, two soybean cultivars, JD19 and LH3, are more salt-tolerant than LD2 because of their higher antioxidant enzyme activities, less ROS accumulation, and higher capacities of $\mathrm{K}^{+}$and $\mathrm{Na}^{+}$homeostasis under salinity. Transcriptomic and metabolomic analyses indicated that JD19 and LH3 have strong adaptive strategies to salt stress. First, increased $\mathrm{N}$ acquisition and assimilation are beneficial for JD19 and LH3 to accumulate amino acids. Second, more amino acid accumulation contributes to osmotic regulation and $\mathrm{N}$ reserve in JD19 and LH3. Third, high N reserve and NUE is advantageous to produce more ROS-scavenging enzymes for salt tolerance. Fourth, high TCA cycle activity in JD19 and LH3 helps in the production of organic acid, NADH, and ATP to support their growth under salt stress. These results may provide theoretical guidance for breeding salt-tolerant soybean cultivars and for sustainable utilization of saline soils.

Supplementary Materials: The following are available online at https:/ / www.mdpi.com/article/10.3 390/ijms222312848/s1.

Author Contributions: J.J., J.W. and Y.B. designed the experiments; G.Z. provided soybean seeds and their cultivation characteristics; J.J., K.L., S.W. and J.Q. performed the experiments; J.J. and J.W. analyzed the data; J.J., X.W. and X.N. wrote the manuscript. All authors have read and agreed to the published version of the manuscript.

Funding: This work was supported by the National Natural Science Foundation of China (31972494), The Open Project of State Biotechnology Research and Application Development Program of Gansu Province (GNSW-2016-23). Foundation of Science and Technology of Gansu Province (20JR5RA288), and Fundamental Research Funds for the Central Universities (lzujbky-2021-kb05). The Fundamental Research Funds for the Central Universities (lzujbky-2021-ey01, lzujbky-2021-kb12) in Lanzhou University, the Open Project of State Key Laboratory of Plateau Ecology and Agriculture, Qinghai University (2021-KF-02), Lanzhou University “Double First-Class" guiding special project-team construction fund-scientific research start-up fee standard (561119206).

Institutional Review Board Statement: Not applicable.

Informed Consent Statement: Not applicable.

Data Availability Statement: The data presented in this study are available in the article and supplementary material.

Conflicts of Interest: The authors declare that they have no competing interests.

\begin{abstract}
Abbreviations
ADP Adenosine diphosphate; ATP Adenosine triphosphate; FDR False discovery rate; MDA Malondialdehyde; NADH Nicotinamide adenine dinucleotide; NUE Nitrogen use efficiency; NUpE Nitrogen uptake efficiency; NUtE Nitrogen utilization efficiency; TCA cycle Tricarboxylic acid cycle.
\end{abstract}

\section{References}

1. Zhu, J.K. Salt and drought stress signal transduction in plants. Annu. Rev. Plant Biol. 2002, 53, 247-273. [CrossRef] [PubMed]

2. Munns, R.; Tester, M. Mechanisms of salinity tolerance. Annu. Rev. Plant Biol. 2008, 59, 651-681. [CrossRef] [PubMed]

3. Rengasamy, P. World salinization with emphasis on Australia. J. Exp. Bot. 2006, 57, 1017-1023. [CrossRef]

4. Tilman, D.; Balzer, C.; Hill, J.; Befort, B.L. Global food demand and the sustainable intensification of agriculture. Proc. Natl. Acad. Sci. USA 2011, 108, 20260-20264. [CrossRef]

5. Yamaguchi, T.; Blumwald, E. Developing salt-tolerant crop plants: Challenges and opportunities. Trends. Plant Sci. 2005, 10, 615-620. [CrossRef]

6. Wilson, R.F. Soybean: Market Driven Research Needs; Springer: New York, NY, USA, 2008. 
7. Bellaloui, N.; Bruns, H.A.; Abbas, H.K.; Mengistu, A.; Fisher, D.K.; Reddy, K.N. Agricultural practices altered soybean seed protein, oil, fatty acids, sugars, and minerals in the Midsouth USA. Front. Plant Sci. 2015, 31, 31. [CrossRef] [PubMed]

8. Garg, B.; Gupta, I. Nodulation and symbiotic nitrogen fixation under salt stress. Curr. Agric. 2000, 24, 23-35.

9. Papiernik, S.K.; Grieve, C.M.; Lesch, S.M.; Yates, S.R. Effects of salinity, imazethapyr, and chlorimuron application on soybean growth and yield. Commun. Soil Sci. Plant Anal. 2005, 36, 951-967. [CrossRef]

10. Abd-Alla, M.; Issa, A.; Ohyama, T. Impact of harsh environmental conditions on nodule formation and dinitrogen fixation of legumes. In Advances in Biology and Ecology of Nitrogen Fixatio; InTech: London, UK, 2014; pp. 131-193.

11. Zhu, J.; Fu, X.; Koo, Y.D.; Zhu, J.K.; Jenney, F.E.; Adams, M.W.; Zhu, Y.; Shi, H.; Yun, D.J.; Hasegawa, P.M. An enhancer mutant of Arabidopsis salt overly sensitive 3 mediates both ion homeostasis and the oxidative stress response. Mol. Cell Biol. 2007, 27, 5214-5224. [CrossRef]

12. Zhu, J.K. Abiotic Stress Signaling and Responses in Plants. Cell 2016, 167, 313-324. [CrossRef]

13. Ismail, A.; Horie, T. Genomics, physiology, and molecular breeding approaches for improving salt tolerance. Annu. Rev. Plant Biol. 2017, 68, 405-434. [CrossRef] [PubMed]

14. Miller, G.; Suzuki, N.; Ciftci-Yilmaz, S.; Mittler, R. Reactive oxygen species homeostasis and signalling during drought and salinity stresses. Plant Cell Environ. 2010, 33, 453-467. [CrossRef] [PubMed]

15. Brini, F.; Masmoudi, K. Ion transporters and abiotic stress tolerance in plants. ISRN Mol. Biol. 2012, 3, 1-13. [CrossRef]

16. Wei, W.; Li, Q.T.; Chu, Y.N.; Reiter, R.J.; Yu, X.M.; Zhu, D.H.; Zhang, W.K.; Ma, B.; Lin, Q.; Zhang, J.S. Melatonin enhances plant growth and abiotic stress tolerance in soybean plants. J. Exp. Bot. 2015, 66, 695-707. [CrossRef]

17. Zhang, D.Y.; Tong, J.F.; He, X.L.; Xu, Z.L.; Xu, L.; Wei, P.P.; Huang, Y.H.; Brestic, M.; Ma, H.X.; Shao, H.B. A novel soybean intrinsic protein gene, GmTIP2;3, involved in responding to osmotic stress. Front. Plant Sci. 2016, 6, 1237. [CrossRef] [PubMed]

18. Yang, Y.; Guo, Y. Elucidating the molecular mechanisms mediating plant salt-stress responses. New Phytol. 2018, 217, 523-539. [CrossRef]

19. Behr, J.H.; Bouchereau, A.; Berardocco, S.; Seal, C.E.; Flowers, T.J.; Zörb, C. Metabolic and physiological adjustment of Suaeda maritima to combined salinity and hypoxia. Ann. Bot. 2017, 119, 965-976. [PubMed]

20. Kumari, A.; Parida, A.K. Metabolomics and network analysis reveal the potential metabolites and biological pathways involved in salinity tolerance of the halophyte Salvadora persica. Environ. Exp. Bot. 2018, 148, 85-99. [CrossRef]

21. Gurmani, A.R.; Bano, A.; Najeeb, U.; Zhang, J.; Khan, S.U.; Flowers, T.J. Exogenously applied silicate and abscisic acid ameliorates the growth of salinity stressed wheat Triticum aestivum L. seedlings through $\mathrm{Na}^{+}$exclusion. Aust. J. Crop Sci. 2013, 7, $1123-1130$.

22. Batista-Silva, W.; Heinemann, B.; Rugen, N.; Nunes-Nesi, A.; Araújo, W.L.; Braun, H.P.; Hildebrandt, T.M. The role of amino acid metabolism during abiotic stress release. Plant Cell Environ. 2019, 42, 1630-1644. [CrossRef]

23. Zhang, Z.; Mao, C.; Shi, Z.; Kou, X. The amino acid metabolic and carbohydrate metabolic pathway play important roles during salt-stress response in tomato. Front. Plant Sci. 2017, 8, 1231. [CrossRef] [PubMed]

24. Huang, L.; Kuang, L.; Li, X.; Wu, L.; Wu, D.; Zhang, G. Metabolomic and transcriptomic analyses reveal the reasons why Hordeum marinum has higher salt tolerance than Hordeum vulgare. Environ. Exp. Bot. 2018, 156, 48-61. [CrossRef]

25. Xiong, X.; Wei, Y.Q.; Chen, J.H.; Liu, N.; Zhang, Y.J. Transcriptome analysis of genes and pathways associated with salt tolerance in alfalfa under non-uniform salt stress. Plant Physiol. Biochem. 2020, 151, 323-333. [CrossRef] [PubMed]

26. Zhang, Y.; Li, D.; Zhou, R.; Wang, X.; Dossa, K.; Wang, L.; Zhang, Y.; Yu, J.; Gong, H.; Zhang, X.; et al. Transcriptome and metabolome analyses of two contrasting sesame genotypes reveal the crucial biological pathways involved in rapid adaptive response to salt stress. BMC Plant Biol. 2019, 191, 66. [CrossRef]

27. Jia, G.; Sha, K.; Feng, X.; Liu, H. Post-thawing metabolite profile and amino acid oxidation of thawed pork tenderloin by HVEF-A short communication. Food Chem. 2019, 291, 16-21. [CrossRef]

28. Xu, G.; Fan, X.; Miller, A.J. Plant nitrogen assimilation and use efficiency. Annu. Rev. Plant Biol. 2012, 63, 153-182. [CrossRef] [PubMed]

29. Nacry, P.; Bouguyon, E.; Gojon, A. Nitrogen acquisition by roots: Physiological and developmental mechanisms ensuring plant adaptation to a fluctuating resource. Plant Soil 2013, 370, 1-29. [CrossRef]

30. Wang, Y.Y.; Cheng, Y.H.; Chen, K.E.; Tsay, Y.F. Nitrate transport, signaling, and use efficiency. Annu. Rev. Plant Biol. 2018, 69, 85-122. [CrossRef]

31. Shahram, K.; Joseph, O.C.; Jonathan, R.; Yaneth, R.C.; Miercke, L.J.W.; Stroud, R.M. Mechanism of ammonia transport by Amt/MEP/Rh: Structure of AmtB at 1.35 A. Science 2004, 305, 1587-1594.

32. Carlos, O.R.; Mora, S.I.; Jorge, T.; Omar, P. PvAMT1;1, a highly selective ammonium transporter that functions as $\mathrm{H}^{+} / \mathrm{NH}_{4}{ }^{+}$ symporter. J. Biol. Chem. 2011, 286, 31113-31122.

33. Chen, T.X.; Johnson, R.; Chen, S.H.; Lv, H.; Zhou, J.L.; Li, C.J. Infection by the fungal endophyte Epichloë bromicola enhances the tolerance of wild barley Hordeum brevisubulatum to salt and alkali stresses. Plant Soil 2018, 428, 353-370. [CrossRef]

34. Wang, J.F.; Tian, P.; Christensen, M.J.; Zhang, X.X.; Li, C.J.; Nan, Z.B. Effect of Epichloë gansuensis endophyte on the activity of enzymes of nitrogen metabolism, nitrogen use efficiency and photosynthetic ability of Achnatherum inebrians under various $\mathrm{NaCl}$ concentrations. Plant Soil 2019, 435, 57-68. [CrossRef]

35. Bian, X.H.; Li, W.; Niu, C.F.; Wei, W.; Hu, Y.; Han, J.Q.; Lu, X.; Tao, J.J.; Jin, M.; Qin, H.; et al. A class B heat shock factor selected for during soybean domestication contributes to salt tolerance by promoting flavonoid biosynthesis. New Phytol. 2020, 1, $268-283$. [CrossRef] [PubMed] 
36. Li, S. Redox modulation matters: Emerging functions for glutaredoxins in plant development and stress responses. Plants 2014, 3, 559-582. [CrossRef] [PubMed]

37. You, J.; Zhang, Y.; Liu, A.; Li, D.; Zhang, X. Transcriptomic and metabolobmic profiling of drought-tolerant and susceptible sesame genotypes in response to drought stress. BMC Plant Biol. 2019, 19, 267. [CrossRef] [PubMed]

38. Guo, Y.; Huang, C.; Xie, Y.; Song, F.; Zhou, X. A tomato glutaredoxin gene SlGRX1 regulates plant responses to oxidative, drought and salt stresses. Planta 2010, 2326, 1499-1509. [CrossRef]

39. Wu, Q.; Hu, Y.; Sprague, S.A.; Kakeshpour, T.; Park, J.; Nakata, P.A.; Cheng, N.; Hirschi, K.D.; White, F.F.; Park, S. Expression of a monothiol glutaredoxin, AtGRXS17, in tomato Solanum lycopersicum enhances drought tolerance. Biochem. Bioph. Res. Commun. 2017, 491, 1034-1039. [CrossRef] [PubMed]

40. Nianiou-Obeidat, I.; Madesis, P.; Kissoudis, C.; Voulgari, G.; Chronopoulou, E.; Tsaftaris, A.; Labrou, N.E. Plant glutathione transferase-mediated stress tolerance: Functions and biotechnological applications. Plant Cell Rep. 2017, 366, 791-805. [CrossRef]

41. Shabala, S. Learning from halophytes: Physiological basis and strategies to improve abiotic stress tolerance in crops. Ann. Bot. 2013, 112, 1209-1221. [CrossRef]

42. Zhao, C.Z.; Wang, X.M.; Wang, X.Y.; Wu, K.L.; Li, P.; Chang, N.; Wang, J.F.; Wang, F.; Li, J.L.; Bi, Y.R. Glucose-6-phosphate dehydrogenase and alternative oxidase are involved in the cross tolerance of highland barley to salt stress and UV-B radiation. J. Plant Physiol. 2015, 181, 83-95. [CrossRef]

43. Chen, C.; Liu, H.; Wang, C.; Liu, Z.; Liu, X.; Zou, L.; Zhao, H.; Yan, Y.; Shi, J.; Chen, S. Metabolomics characterizes metabolic changes of Apocyni Veneti Folium in response to salt stress. Plant Physiol. Bioch. 2019, 144, 187-196. [CrossRef]

44. Zhang, J.; Yang, D.; Li, M.; Shi, L. Metabolic profiles reveal changes in wild and cultivated soybean seedling leaves under salt stress. PLoS ONE 2016, 11, e0159622. [CrossRef]

45. Zhang, J.; Zhang, Y.; Du, Y.; Chen, S.; Tang, H. Dynamic metabonomic responses of tobacco (Nicotiana tabacum) plants to salt stress. J. Proteome Res. 2011, 10, 1904-1914. [CrossRef] [PubMed]

46. Khedr, A.H.A.; Abbas, M.A.; Wahid, A.A.A.; Quick, W.P.; Abogadallah, G.M. Proline induces the expression of salt-stressresponsive proteins and may improve the adaptation of Pancratium maritimum L. to salt-stress. J. Exp. Bot. 2003, 54, $2553-2562$. [CrossRef] [PubMed]

47. Vieira, E.A.; Silva, M.d.G.; dos Santos Gomes, A.; Urakawa, A.H.; Barros, A.L. Carbon-nitrogen metabolism and oxidative stress in young plants of Dipteryx alata Vog. subjected to seasonal water regimes in the Cerrado. Environ. Exp. Bot. 2021, $183,104361$. [CrossRef]

48. Pires, M.V.; Pereira, A.A., Jr.; Medeiros, D.B.; Daloso, D.M.; Pham, P.A.; Barros, K.A.; Fernie, A.R. The influence of alternative pathways of respiration that utilize branched-chain amino acids following water shortage in Arabidopsis. Plant Cell Environ. 2016, 39, 1304-1319. [CrossRef] [PubMed]

49. Fukushima, A.; Kusano, M. A network perspective on nitrogen metabolism from model to crop plants using integrated 'omics' approaches. J. Exp. Bot. 2014, 65, 5619-5630. [CrossRef] [PubMed]

50. Leberecht, M.; Dannenmann, M.; Tejedor, J.; Simon, J.; Rennenberg, H.; Polle, A. Segregation of nitrogen use between ammonium and nitrate of ectomycorrhizas and beech trees. Plant Cell Environ. 2016, 39, 2691-2700. [CrossRef]

51. Casartelli, A.; Riewe, D.; Hubberten, H.M.; Altmann, T.; Hoefgen, R.; Heuer, S. Exploring traditional aus-type rice for metabolites conferring drought tolerance. Rice 2018, 11, 9. [CrossRef]

52. Yu, Y.C.; Xu, T.; Li, X.; Tang, J.; Ma, D.F.; Li, Z.Y.; Sun, J. NaCl-induced changes of ion homeostasis and nitrogen metabolism in two sweet potato Ipomoea batatas L. cultivars exhibit different salt tolerance at adventitious root stage. Environ. Exp. Bot. 2016, 129, 23-36. [CrossRef]

53. Wang, H.; Zhang, M.S.; Guo, R.; Shi, D.C.; Liu, B.; Lin, X.Y.; Yang, C.W. Effects of salt stress on ion balance and nitrogen metabolism of old and young leaves in rice Oryza sativa L. BMC Plant Biol. 2012, 12, 194. [CrossRef] [PubMed]

54. Botella, M.A.; Martínez, V.; Nieves, M.; Cerdá, A. Effect of salinity on the growth and nitrogen uptake by wheat seedlings. J. Plant Nutr. 1997, 20, 793-804. [CrossRef]

55. Zhang, C.X.; Meng, S.; Li, Y.M.; Zhao, Z. Net $\mathrm{NH}_{4}{ }^{+}$and $\mathrm{NO}_{3}{ }^{-}$fluxes, and expression of $\mathrm{NH}_{4}{ }^{+}$and $\mathrm{NO}_{3}{ }^{-}$transporter genes in roots of Populus simonii after acclimation to moderate salinity. Trees 2014, 28, 1813-1821. [CrossRef]

56. Silveira, J.A.G.; Viégas, R.D.A.; Rocha, I.M.A.D.; Moreira, R.D.A.; Oliveira, J.T.A. Proline accumulation and glutamine synthetase activity are increased by salt-induced proteolysis in cashew leaves. J. Plant Physiol. 2003, 160, 115-123. [CrossRef]

57. Wang, Z.Q.; Yuan, Y.Z.; Ou, J.Q.; Lin, Q.H.; Zhang, C.F. Glutamine synthetase and glutamate dehydrogenase contribute differentially to proline accumulation in leaves of wheat Triticum aestivum seedlings exposed to different salinity. J. Plant Physiol. 2007, 164, 695-701. [CrossRef]

58. Jabeen, N.; Ahmad, R. Growth response and nitrogen metabolism of sunflower Helianthus annuus L. to vermicompost and biogas slurry under salinity stress. J. Plant Nutr. 2017, 40, 104-114. [CrossRef]

59. Surabhi, G.K.; Reddy, A.M.; Kumari, G.J.; Sudhakar, C. Modulations in key enzymes of nitrogen metabolism in two high yielding genotypes of mulberry Morus alba L. with differential sensitivity to salt stress. Environ. Exp. Bot. 2008, 64, 171-179. [CrossRef]

60. Betti, M.; Udvardi, M.K.; Monza, J. Deficiency in plastidic glutamine synthetase alters proline metabolism and transcriptomic response in Lotus japonicus under drought stress. New Phytol. 2010, 188, 1001-1013.

61. Rong, Q.Q.; Liu, J.T.; Cai, Y.P.; Lu, Z.H.; Zhao, Z.Z.; Yue, W.C.; Xia, J.B. Leaf carbon, nitrogen and phosphorus stoichiometry of Tamarix chinensis Lour. in the Laizhou Bay coastal wetland, China. Ecol. Eng. 2015, 76, 57-65. [CrossRef] 
62. Song, M.L.; Chai, Q.; Li, X.Z.; Yao, X.; Li, C.J.; Christensen, M.J.; Nan, Z.B. An asexual Epichloë endophyte modifies the nutrient stoichiometry of wild barley Hordeum brevisubulatum under salt stress. Plant Soil 2015, 387, 153-165. [CrossRef]

63. Cabot, C.; Sibole, J.V.; Barceló, J.; Poschenrieder, C. Lessons from crop plants struggling with salinity. Plant Sci. 2014, 226 , 2-13. [CrossRef]

64. Khan, M.H.; Meghvansi, M.K.; Gupta, R.; Veer, V.; Singh, L.; Kalita, M.C. Foliar spray with vermiwash modifies the Arbuscular mycorrhizal dependency and nutrient stoichiometry of Bhut Jolokia Capsicum assamicum. PLoS ONE 2014, 9, e92318.

65. Kiani-Pouya, A.; Roessner, U.; Jayasinghe, N.S.; Lutz, A.; Rupasinghe, T.; Bazihizina, N.; Bohm, J.; Alharbi, S.; Hedrich, R.; Shabala, S. Epidermal bladder cells confer salinity stress tolerance in the Halophyte quinoa and Atriplex species. Plant Cell Environ. 2017, 409, 1900-1915. [CrossRef]

66. Gong, Q.; Li, P.; Ma, S.; Rupassara, S.I.; Bohnert, H.J. Salinity stress adaptation competence in the extremophile Thellungiella halophila in comparison with its relative Arabidopsis thaliana. Plant J. 2005, 445, 826-839. [CrossRef] [PubMed]

67. Liu, X.; Wu, H.; Ji, C.; Wei, L.; Zhao, J.; Yu, J. An integrated proteomic and metabolomic study on the chronic effects of mercury in Suaeda salsa under an environmentally relevant salinity. PLoS ONE 2013, 85, e64041. [CrossRef] [PubMed]

68. Patterson, J.H.; Newbigin, E.; Tester, M.; Bacic, A.; Roessner, U. Metabolic responses to salt stress of barley Hordeum vulgare L. cultivars, Sahara and Clipper, which differ in salinity tolerance. J. Exp. Bot. 2009, 60, 4089-4103.

69. Shu, L.; Lou, Q.; Ma, C.; Ding, W.; Zhou, J.; Wu, J.; Feng, F.; Lu, X.; Luo, L.; Xu, G.; et al. Genetic, proteomic and metabolic analysis of the regulation of energy storage in rice seedlings in response to drought. Proteomics 2011, 11, 4122-4138. [CrossRef] [PubMed]

70. Li, L.; Xing, W.W.; Shao, Q.S.; Shu, S.; Sun, J.; Guo, S.R. The effects of grafting on glycolysis and the tricarboxylic acid cycle in $\mathrm{Ca}\left(\mathrm{NO}_{3}\right)_{2}$-stressed cucumber seedlings with pumpkin as rootstock. Acta Physiol. Plant 2015, 37, 259. [CrossRef]

71. Rangani, J.; Parida, A.K.; Panda, A.; Kumari, A. Coordinated changes in antioxidative enzymes protect the photosynthetic machinery from salinity induced oxidative damage and confer salt tolerance in an extreme halophyte Salvadora persica L. Front. Plant Sci. 2016, 7, 1-18. [CrossRef]

72. Caballero, B.; Trugo, L.; Finglas, P. Encyclopedia of food sciences and nutrition. In Encyclopedia of Food Sciences and Nutrition, 2nd ed.; Academic Press: Cambridge, MA, USA, 2003; Volume 1-10.

73. Hodgesm, D.M.; DeLong, J.M.; Forney, C.F.; Prange, R.K. Improving the thiobarbituric acid-reactive-substances assay for estimating lipid peroxidation in plant tissues containing anthocyanin and other interfering compounds. Planta 1999, $207,604-611$. [CrossRef]

74. Yang, L.; Wang, X.; Chang, N.; Nan, W.; Wang, S.; Ruan, M.; Sun, L.; Li, S.; Bi, Y.R. Cytosolic glucose-6-phosphate dehydrogenase is involved in seed germination and root growth under salinity in Arabidopsis. Front. Plant Sci. 2019, 10, 182. [CrossRef]

75. Yang, T.; Yuan, G.; Zhang, Q.; Xuan, L.; Li, J.; Zhou, L.; Shi, H.; Wang, X.; Wang, C. Transcriptome and metabolome analyses reveal the pivotal role of hydrogen sulfide in promoting submergence tolerance in Arabidopsis. Environ. Exp. Bot. 2021, 183, 104365. [CrossRef]

76. Kim, D.; Langmead, B.; Salzberg, S.L. HISAT: A fast spliced aligner with low memory requirements. Nat. Methods 2015, 12, 357-360. [CrossRef] [PubMed]

77. Mortazavi, A.; Williams, B.A.; McCue, K.; Schaeffer, L.; Wold, B. Mapping and quantifying mammalian transcriptomes by RNA-Seq. Nat. Methods 2008, 5, 621-628. [CrossRef] [PubMed]

78. Bindea, G.; Mlecnik, B.; Hackl, H.; Charoentong, P.; Tosolini, M.; Kirilovsky, A.; Fridman, W.H.; Pagès, F.; Trajanoski, Z.; Galon, J. ClueGO: A Cytoscape plug-in to decipher functionally grouped gene ontology and pathway annotation networks. Bioinformatics 2009, 25, 1091-1093. [CrossRef]

79. Dunn, W.B.; Broadhurst, D.; Begley, P.; Zelenal, E.; Francis-McIntyre, S.; Anderson, N.; Brown, M.; Knowles, D.J.; Halsall, A.; Haselden, N.J.; et al. Procedures for large-scale metabolic profiling of serum and plasma using gas chromatography and liquid chromatography coupled to mass spectrometry. Nat. Protoc. 2011, 7, 1060-1083. [CrossRef]

80. Hou, W.; Wang, J.; Christensen, M.J.; Liu, J.; Zhang, Y.; Liu, Y.; Cheng, C. Metabolomics insights into the mechanism by which Epichloë gansuensis endophyte increased Achnatherum inebrians tolerance to low nitrogen stress. Plant Soil 2021, 463, 487-508. [CrossRef]

81. Wang, J.F.; Nan, Z.B.; Christensen, M.J.; Zhang, X.X.; Tian, P.; Zhang, Z.X.; Niu, X.L.; Gao, P.; Chen, T.; Ma, L.X. Effect of Epichloë gansuensis endophyte on the nitrogen metabolism, nitrogen use efficiency, and stoichiometry of Achnatherum inebrians under nitrogen limitation. J. Agric. Food Chem. 2018, 66, 4022-4031. [CrossRef]

82. Li, B.; Qiu, J.; Jayakannan, M.; Xu, B.; Li, Y.; Mayo, G.M.; Tester, M.; Gilliham, M.; Roy, S.J. AtNPF2.5 modulates chloride (Cl ${ }^{-}$) efflux from roots of Arabidopsis thaliana. Front. Plant Sci. 2017, 7, 2013. [CrossRef]

83. Coelho, E.M.; da Silva Padilha, C.V.; Miskinis, G.A.; de Sá, A.G.B.; Pereira, G.E.; de Azevêdo, L.C.; dos Santos Lima, M. Simultaneous analysis of sugars and organic acids in wine and grape juices by HPLC: Method validation and characterization of products from northeast Brazil. J. Food Compos. Anal. 2018, 66, 160-167. [CrossRef]

84. Du, S.; Zhang, Y.; Lin, X.Y.; Wang, Y.; Tang, C.X. Regulation of nitrate reductase by nitric oxide in Chinese cabbage pakchoi Brassica chinensis L. Plant Cell Environ. 2008, 31, 195-204. [CrossRef]

85. Singh, R.P.; Srivastava, H.S. Increase in glutamate synthase NADH activity in maize seedlings in response to nitrate and ammonium nitrogen. Physiol. Plant 1986, 66, 413-416. [CrossRef]

86. Wang, F.; Wang, X.; Zhao, C.; Wang, J.; Li, P.; Dou, Y.; Bi, Y. Alternative pathway is involved in the tolerance of highland barley to the low-nitrogen stress by maintaining the cellular redox homeostasis. Plant Cell Rep. 2016, 352, 317-328. [CrossRef] [PubMed] 
87. Millar, A.H.; Knorpp, C.; Leaver, C.J.; Hill, S.A. Plant mitochondrial pyruvate dehydrogenase complex: Purification and identification of catalytic components in potato. Biochem. J. 1998, 334, 571-576. [CrossRef]

88. Jenner, H.L.; Winning, B.M.; Millar, A.H.; Tomlinson, K.L.; Leaver, C.J.; Hill, S.A. NAD malic enzyme and the control of carbohydrate metabolism in potato tubers. Plant Physiol. 2001, 126, 1139-1149. [CrossRef] [PubMed]

89. Pekovich, S.R.; Martin, P.R.; Singleton, C.K. Thiamine pyrophosphate-requiring enzymes are altered during pyrithiamine-induced thiamine deficiency in cultured human lymphoblasts. J. Nutri. 1996, 126, 1791-1798.

90. Schirawski, J.; Unden, G. Anaerobic respiration of Bacillus macerans with fumarate, TMAO, nitrate and nitrite and regulation of the pathways by oxygen and nitrate. Arch. Microbiol. 1995, 163, 148-154. [CrossRef] 